\title{
North Atlantic Eddy-Driven Jet in Interglacial and Glacial Winter Climates
}

\author{
Niklaus Merz AND CHRistoph C. RAIBLE \\ Climate and Environmental Physics, and Oeschger Centre for Climate Change Research, University of Bern, \\ Bern, Switzerland
}

TIM WOOLLINGS

Atmospheric Physics, Clarendon Laboratory, Oxford, United Kingdom

(Manuscript received 29 July 2014, in final form 9 March 2015)

\begin{abstract}
The atmospheric westerly flow in the North Atlantic (NA) sector is dominated by atmospheric waves or eddies generating via momentum flux convergence, the so-called eddy-driven jet. The position of this jet is variable and shows for the present-day winter climate three preferred latitudinal states: a northern, central, and southern position in the NA. Here, the authors analyze the behavior of the eddy-driven jet under different glacial and interglacial boundary conditions using atmosphere-land-only simulations with the CCSM4 climate model. As state-of-the-art climate models tend to underestimate the trimodality of the jet latitude, the authors apply a bias correction and successfully extract the trimodal behavior of the jet within CCSM4. The analysis shows that during interglacial times (i.e., the early Holocene and the Eemian) the preferred jet positions are rather stable and the observed multimodality is the typical interglacial character of the jet. During glacial times, the jet is strongly enhanced, its position is shifted southward, and the trimodal behavior vanishes. This is mainly due to the presence of the Laurentide ice sheet (LIS). The LIS enhances stationary waves downstream, thereby accelerating and displacing the NA eddy-driven jet by anomalous stationary momentum flux convergence. Additionally, changes in the transient eddy activity caused by topography changes as well as other glacial boundary conditions lead to an acceleration of the westerly winds over the southern NA at the expense of more northern areas. Consequently, both stationary and transient eddies foster the southward shift of the NA eddy-driven jet during glacial winter times.
\end{abstract}

\section{Introduction}

Much of the observed weather and climate variability in the North Atlantic (NA) area is associated with variations in the NA eddy-driven jet stream, which manifests itself as prevailing westerly winds in the midlatitudes. The eddy-driven jet is generated by momentum and heat forcing associated with transient midlatitude eddies in contrast to the subtropical jet, which results from angular momentum transport of the Hades circulation that is driven by thermal convection in the tropics. Contrary to many other midlatitude regions, the subtropical and the eddy-driven branch of the jet can be spatially distinguished in the NA sector during winter (e.g.,

Corresponding author address: Niklaus Merz, Climate and Environmental Physics, Physics Institute, University of Bern, Sidlerstrasse 5, 3012 Bern, Switzerland.

E-mail: merz@climate.unibe.ch
Eichelberger and Hartmann 2007). The relatively weak equatorial heat sources in the Atlantic sector prohibit a strong subtropical jet and disconnect tropical from extratropical variability over the NA. Consequently, the winter zonal wind variability in the NA sector (i.e., north of $20^{\circ} \mathrm{N}$ ) is primarily eddy driven ( $\mathrm{Li}$ and Wettstein 2012). This is in contrast to the Pacific sector, where the midlatitude winter jet is forced by both the tropical thermal heating and the eddies.

The NA winter eddy-driven jet is variable on daily to decadal time scales. The variability in terms of jet speed and latitudinal position is closely tied to the variability of the NA storm track (Wettstein and Wallace 2010) through eddy-mean flow interactions [see Hartmann (2007) for a review]. Furthermore, the NA jet stream variability can at least partially be described by extratropical teleconnection patterns such as the North Atlantic Oscillation (NAO) or the east Atlantic (EA) pattern (Athanasiadis et al. 2010). Based on reanalysis data of 
recent decades, Woollings et al. (2010, hereinafter WO10) identified three preferred latitudinal positions of the NA eddy-driven jet in winter: the so-called northern, central, and southern jet regimes, which are regarded as favored states in the two-dimensional NAO-EA space. Each jet regime is associated with anomalous patterns of temperature, precipitation, and storm activity, thus having considerable societal impact. Extending the WO10 analysis to the Twentieth Century Reanalysis (20CR) reaching back to 1871 (Compo et al. 2011), the multimodality of the NA jet is confirmed as the dominant characteristic for the present-day winter climate (Woollings et al. 2014).

The shape of the NA eddy-driven jet as well as the NA storm track are influenced by the stationary wave pattern arising from topography and sea surface temperature forcing (Brayshaw et al. 2009). More precisely, the present-day characteristics of the North American continent interacts with the westerly flow and generates the well-known southwest-northeast tilt in both the storm track and the jet over the NA domain. Consequently, we expect modifications in these flow patterns on time scales coming along with significant changes in Northern Hemisphere (NH) topographic or thermal forcing (e.g., Hoskins and Karoly 1981). In the past, substantial variations in the $\mathrm{NH}$ topography have occurred on the time scale of glacial-interglacial cycles with the growth and retreat of continental-size ice sheets.

The sensitivity of the atmospheric dynamics to glacial versus interglacial boundary conditions has been a prominent research topic for the climate science community for many decades. Thereby, many studies could benefit from the coordinated modeling efforts in the framework of the Paleoclimate Modeling Intercomparison Project (PMIP), which focuses (among others) on the climate of the mid-Holocene $(6 \mathrm{ka})$ and Last Glacial Maximum (LGM). For mid-Holocene conditions, the behavior of the NA eddy-driven jet was presumably similar to the present day as only minor changes in the structure of the NH atmospheric variability (e.g., the NAO) are found (Gladstone et al. 2005). In contrast, distinct responses of the large-scale atmospheric circulation have been observed for fully glacial conditions during the LGM (e.g., Cook and Held 1988; Kageyama and Valdes 2000; Laine et al. 2009), and the presence of a large Laurentide ice sheet (LIS) has been identified as the primary driver (Pausata et al. 2011; Hofer et al. 2012a). However, only a few studies assessed the glacial behavior of the NA jet stream and its links to the transient eddies in detail ( $\mathrm{Li}$ and Battisti 2008; Laine et al. 2009; Riviere et al. 2010). Important results are that the NA LGM jet is both more zonally oriented and accelerated despite a reduction in the eddy activity over the NA area (Li and Battisti 2008).
Further, the latitudinal fluctuations of the NA eddydriven jet are much weaker (Riviere et al. 2010) for the LGM and the modified jet stream variability manifests itself as a so-called glacial NAO (Justino and Peltier 2005; Justino et al. 2005) that has little in common with the characteristics of the present-day NAO.

In this study we thoroughly investigate the behavior of the NA winter eddy-driven jet for various glacial and interglacial boundary conditions using simulations with the Community Climate System Model, version 4 (CCSM4). The two overall objectives are 1) to determine the key differences between glacial and interglacial NA eddy-driven jet characteristics and 2) to compare different interglacial periods in order to test whether the observed NA jet behavior (e.g., the multimodality in latitudinal position) is unique to the presentday climate or rather a typical interglacial feature.

The remainder of this paper is structured as follows: Section 2 describes the model simulations and the methods used. Section 3 contains a brief validation of the model's representation of the present-day NA eddydriven jet compared to reanalysis data. The results of the paleoclimate simulations are then presented with respect to the winter mean jet structure (section 4), followed by the analysis of concurrent changes in stationary waves and transient eddy activity (section 5). In addition, the intraseasonal jet variability for interglacial and glacial winter climates is assessed in section 6 . Finally, the results are discussed and concluded in section 7 .

\section{Data and methods}

The study is based on simulations performed with the CCSM4 model developed at the National Center for Atmospheric Research (Gent et al. 2011). Additionally, we use ERA-Interim data covering 1979-2012 (Dee et al. 2011) as an observational reference for model evaluation. All analyses are based on daily model output and restricted to winter [December-February (DJF)].

\section{a. Climate model simulations}

The CCSM4 is used with its atmosphere-land-only setup (F-compset) that couples the Community Atmosphere Model, version 4 (CAM4; Neale et al. 2010) to the Community Land Model, version 4 (CLM4; Oleson et al. 2010). The setup uses monthly mean sea ice cover and sea surface temperatures (SSTs) as prescribed lower boundary conditions. The Community Ice Code, version 4 (CICE4; Hunke and Lipscomb 2008) is set to its thermodynamic-only mode so sea ice concentration fields are prescribed but surface fluxes through the ice are computed by taking into account snow depth, albedo, and surface temperature (as simulated by the 
TABLE 1. List of model simulations and the forcing used in the experiments. Present-day levels are denoted as pd, and preindustrial levels are denoted as pi. SST and sea ice fields are outputs of corresponding fully coupled CCSM3 simulations (either with $1^{\circ}$ or $3^{\circ}$ resolution), except for AMIP, where data from Hurrell et al. (2008) are used. Note that AMIP also uses observed transient GHG concentrations in contrast to all other simulations where GHG concentrations are fixed at the attributed level. Solar forcing is expressed as total solar irradiance (TSI) and set to preindustrial levels in all paleoclimate simulations. The different implemented ice sheets are illustrated in Fig. 1.

\begin{tabular}{|c|c|c|c|c|c|c|c|}
\hline Simulation & $\begin{array}{c}\text { Orbital } \\
\text { parameters }\end{array}$ & SST/sea ice & $\begin{array}{c}\mathrm{CO}_{2} \\
(\mathrm{ppm})\end{array}$ & $\begin{array}{l}\mathrm{CH}_{4} \\
\text { (ppb) }\end{array}$ & $\begin{array}{l}\mathrm{N}_{2} 0 \\
(\mathrm{ppb})\end{array}$ & TSI $\left(\mathrm{W} \mathrm{m}^{-2}\right)$ & Ice sheets \\
\hline \multicolumn{8}{|l|}{ Present day } \\
\hline AMIP & $\mathrm{pd}$ & obs & obs & obs & obs & 1361.8 & $\mathrm{pd}$ \\
\hline PD1 & $\mathrm{pd}$ & $\mathrm{pd} / 1^{\circ}$ & 354 & 1694 & 310 & 1361.8 & pd \\
\hline PI1 & $\mathrm{pd}$ & $\mathrm{pi} / 1^{\circ}$ & 280 & 760 & 270 & 1360.9 & $\mathrm{pd}$ \\
\hline PD3 & $\mathrm{pd}$ & $\mathrm{pd} / 3^{\circ}$ & 354 & 1694 & 310 & 1361.8 & pd \\
\hline $\mathrm{PI} 3$ & $\mathrm{pd}$ & $\mathrm{pi} / 3^{\circ}$ & 280 & 760 & 270 & 1360.9 & $\mathrm{pd}$ \\
\hline \multicolumn{8}{|c|}{ Early Holocene } \\
\hline $\mathrm{EH}_{\mathrm{PD}}$ & $8 \mathrm{ka}$ & $8 \mathrm{ka} / 3^{\circ}$ & 280 & 760 & 270 & 1360.9 & $\mathrm{pd}$ \\
\hline $\mathrm{EH}_{7 \mathrm{ka}}$ & $8 \mathrm{ka}$ & $8 \mathrm{ka} / 3^{\circ}$ & 280 & 760 & 270 & 1360.9 & $7 \mathrm{ka}$ \\
\hline $\mathrm{EH}_{8 \mathrm{ka}}$ & $8 \mathrm{ka}$ & $8 \mathrm{ka} / 3^{\circ}$ & 280 & 760 & 270 & 1360.9 & $8 \mathrm{ka}$ \\
\hline $\mathrm{EH}_{9 \mathrm{ka}}$ & $8 \mathrm{ka}$ & $8 \mathrm{ka} / 3^{\circ}$ & 280 & 760 & 270 & 1360.9 & $9 \mathrm{ka}$ \\
\hline \multicolumn{8}{|l|}{ Eemian } \\
\hline $\mathrm{EEM}_{\mathrm{PD}}$ & $125 \mathrm{ka}$ & $125 \mathrm{ka} / 3^{\circ}$ & 272 & 622 & 259 & 1360.9 & $\mathrm{pd}$ \\
\hline $\mathrm{EEM}_{\mathrm{r} 1}$ & $125 \mathrm{ka}$ & $125 \mathrm{ka} / 3^{\circ}$ & 272 & 622 & 259 & 1360.9 & $\mathrm{EEM}_{\mathrm{r} 1}$ \\
\hline $\mathrm{EEM}_{\mathrm{r} 2}$ & $125 \mathrm{ka}$ & $125 \mathrm{ka} / 3^{\circ}$ & 272 & 622 & 259 & 1360.9 & $\mathrm{EEM}_{\mathrm{r} 2}$ \\
\hline $\mathrm{EEM}_{\mathrm{r} 3}$ & $125 \mathrm{ka}$ & $125 \mathrm{ka} / 3^{\circ}$ & 272 & 622 & 259 & 1360.9 & $\mathrm{EEM}_{\mathrm{r} 3}$ \\
\hline $\mathrm{EEM}_{\mathrm{r} 4}$ & $125 \mathrm{ka}$ & $125 \mathrm{ka} / 3^{\circ}$ & 272 & 622 & 259 & 1360.9 & $\mathrm{EEM}_{\mathrm{r} 4}$ \\
\hline \multicolumn{8}{|l|}{ Glacial } \\
\hline LGM & $21 \mathrm{ka}$ & $21 \mathrm{ka} / 1^{\circ}$ & 185 & 350 & 200 & 1360.9 & LGM \\
\hline MIS4 $_{\text {lowLIS }}$ & $65 \mathrm{ka}$ & $65 \mathrm{ka} / 1^{\circ}$ & 205 & 460 & 210 & 1360.9 & low LIS \\
\hline MIS4 $_{67}$ & $65 \mathrm{ka}$ & $65 \mathrm{ka} / 1^{\circ}$ & 205 & 460 & 210 & 1360.9 & 67\% LGM \\
\hline MIS4 $_{\text {loeFS }}$ & $65 \mathrm{ka}$ & $65 \mathrm{ka} / 1^{\circ}$ & 205 & 460 & 210 & 1360.9 & low FS \\
\hline MIS4 $_{\text {LGM }}$ & $65 \mathrm{ka}$ & $65 \mathrm{ka} / 1^{\circ}$ & 205 & 460 & 210 & 1360.9 & LGM \\
\hline MIS $_{125}$ & $65 \mathrm{ka}$ & $65 \mathrm{ka} / 1^{\circ}$ & 205 & 460 & 210 & 1360.9 & $125 \%$ LGM \\
\hline \multicolumn{8}{|l|}{$\begin{array}{l}\text { Sensitivity } \\
\quad \text { experiments }\end{array}$} \\
\hline $\mathrm{PI}_{\mathrm{LGM}}$ & $\mathrm{pd}$ & $\mathrm{pi} / 1^{\circ}$ & 280 & 760 & 270 & 1360.9 & LGM \\
\hline $\mathrm{LGM}_{\mathrm{PD}}$ & $21 \mathrm{ka}$ & $21 \mathrm{ka} / 1^{\circ}$ & 185 & 350 & 200 & 1360.9 & pd \\
\hline
\end{tabular}

atmospheric component). The horizontal resolution is $0.9^{\circ} \times 1.25^{\circ}$ in all components, whereas the vertical resolution in the atmosphere is 26 layers.

We have performed a total of 22 time-slice simulations (with a length of $30 \mathrm{yr}$ plus $3 \mathrm{yr}$ of spinup phase) for different periods of the last interglacial-glacial cycle. More precisely, the set of simulations includes experiments for present-day/preindustrial conditions, the early Holocene ( $8 \mathrm{ka})$, the Last Glacial Maximum (21 ka), the Marine Isotope Stage 4 (MIS4; $65 \mathrm{ka}$ ), and the Eemian interglacial $(125 \mathrm{ka})$. The external forcing is held constant throughout each simulation. Please see Table 1 for an overview of the simulations and the implemented forcings. Most of the simulations have been previously published and discussed. Therefore, only a brief summary on the setup of these simulations is given here. The early Holocene simulations are presented in Merz et al. (2013), the Eemian experiments are presented in Merz et al. (2014a,b), and the glacial simulations are presented in Hofer et al. (2012a,b).
The present-day category (Table 1) consists of five simulations that use either present-day or preindustrial boundary conditions. The AMIP simulation [described as $\mathrm{PD}_{\mathrm{TR}}$ in Hofer et al. (2012a)] uses transient 1971-2000 external forcing as well as SST and sea ice data from Hurrell et al. (2008) as prescribed lower boundary conditions. Additionally, two present-day simulations (PD1 and PD3) and two preindustrial simulations (PI1 and PI3) are generated, which use output from fully coupled CCSM3 simulations as lower boundary conditions. These simulations are necessary to have respective control simulations for the paleoclimate simulations, which themselves are also forced with SSTs and sea fields of fully coupled CCSM3 simulations of the corresponding climate epoch (i.e., early Holocene, Eemian, LGM, and MIS4). As the CCSM3 paleoclimate simulations were generated with either $1^{\circ}$ or $3^{\circ}$ resolution of the ocean and sea ice component, two kinds of control simulations (PD1/PI1 and PD3/PI3, respectively) are necessary. PD1 and PI1 were previously presented in Hofer et al. (2012a,b), 
a) interglacial topographies

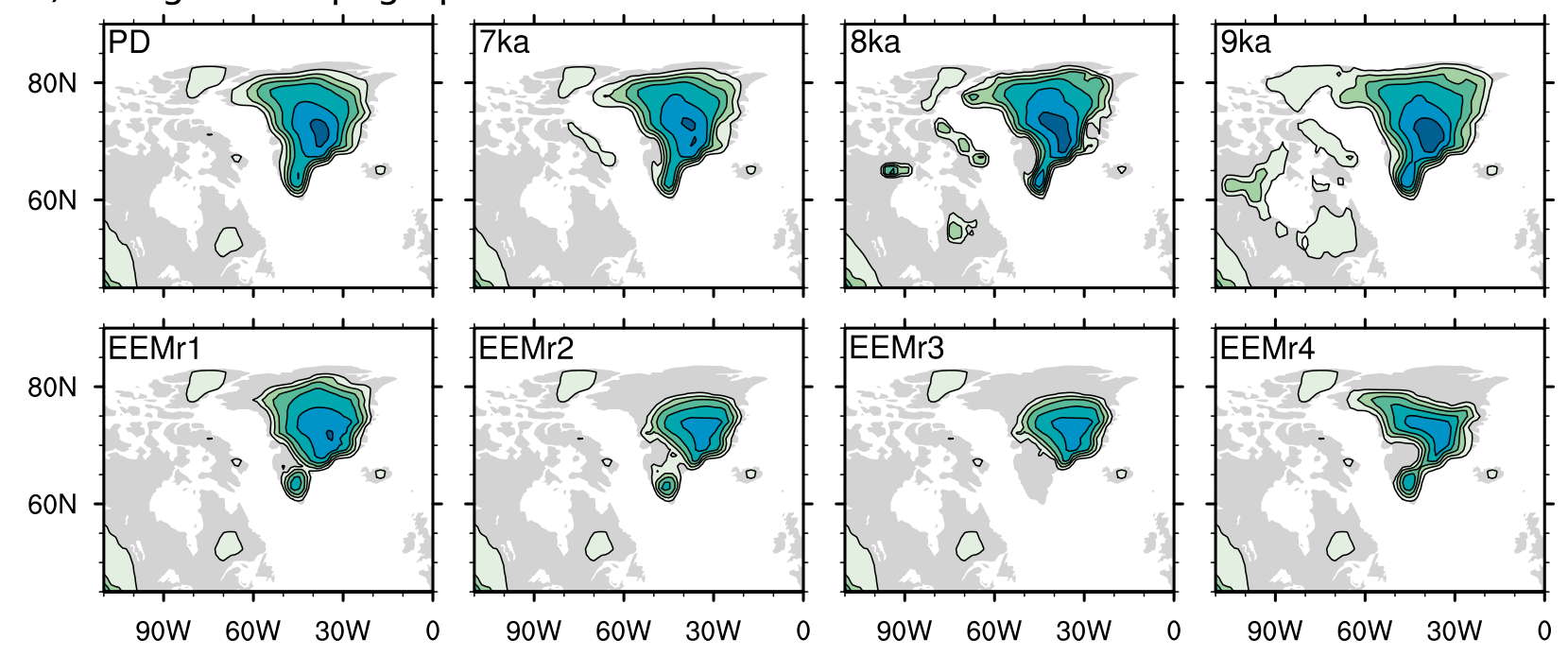

b) glacial topographies
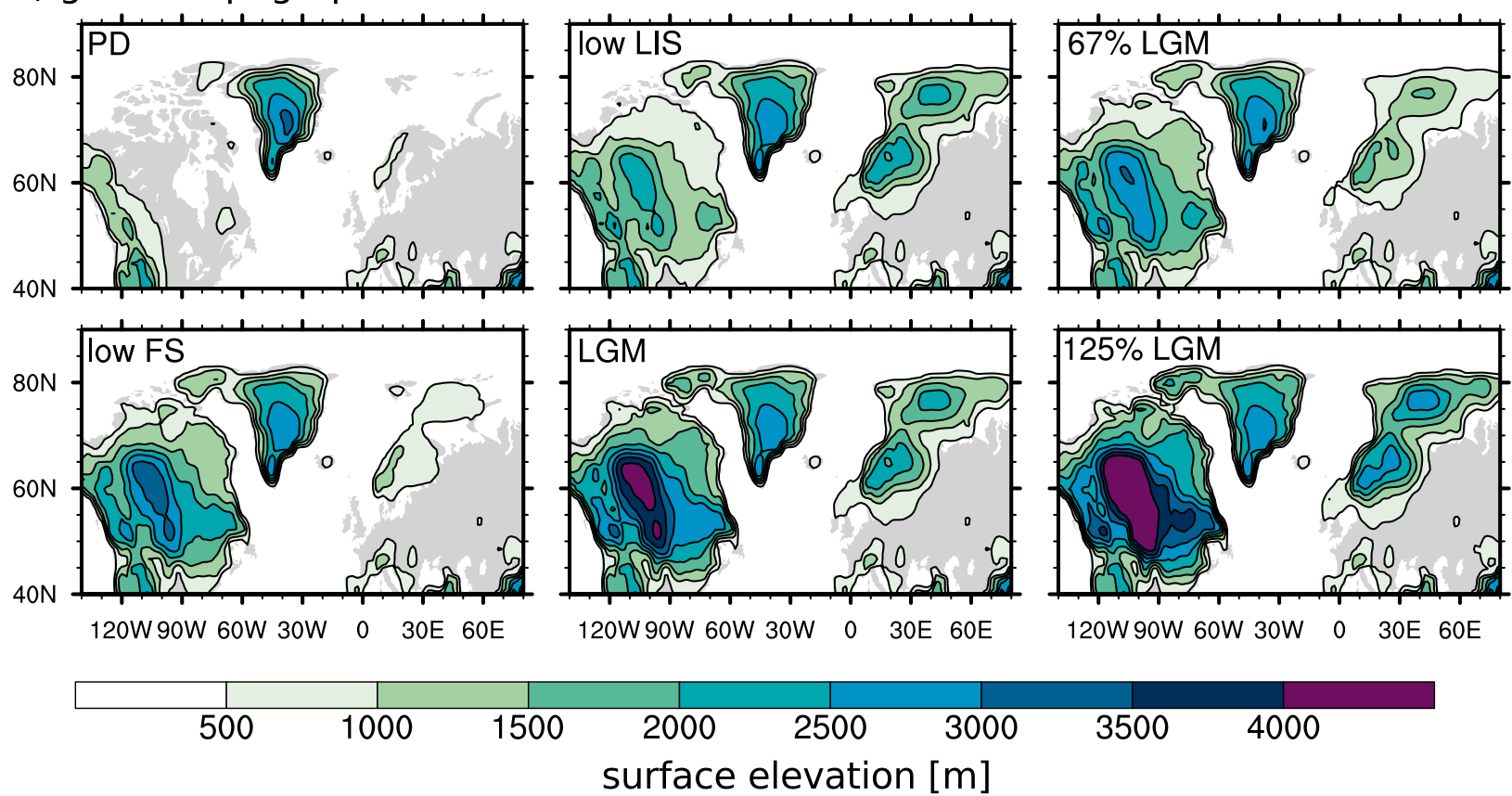

FIG. 1. Northern Hemisphere surface elevation (m) after implementation of the respective ice sheets for (a) the interglacial and (b) the glacial simulations. The glacial topographies are sorted according to their height of the Laurentide ice sheet.

whereas PD3 and PI3 are described in more detail in Merz et al. (2013, 2014a). Note also that the AMIP, PD1, and PD3 simulations are used for model validation (comparing with ERA-Interim), whereas the PI1 and PI3 serve as control simulations for the paleoclimate experiments.

For the early Holocene epoch, we use a set of four experiments with the same 8-ka external forcing (Table 1) but different $\mathrm{NH}$ ice-sheet topographies. In $\mathrm{EH}_{\mathrm{PD}}$ the present-day mask is used. $\mathrm{EH}_{7 \mathrm{ka}}, \mathrm{EH}_{8 \mathrm{ka}}$, and $\mathrm{EH}_{9 \mathrm{ka}}$ use ice-sheet reconstructions for 7, 8, and $9 \mathrm{ka}$, respectively (Peltier 2004). These topography changes include moderate deviations from the present-day topography (Fig. 1a) with some lower areas over the North American continent due to the postglacial rebound effect and some additional topographic features in the form of remnants of the LIS around the Hudson Bay.

A second set of interglacial simulations consists of five Eemian simulations with 125-ka external forcing 
(Table 1). Besides a control simulation $\left(\mathrm{EEM}_{\mathrm{PD}}\right)$ that uses the present-day topography, four simulations $\left(\mathrm{EEM}_{\mathrm{r} 1}-\mathrm{EEM}_{\mathrm{r} 4}\right)$ are available that include a smaller Greenland ice sheet (GrIS), as estimated by two icesheet modeling studies (Robinson et al. 2011; Born and Nisancioglu 2012). As displayed in Fig. 1a, the EEM ${ }_{\mathrm{r} 1}$ topography just moderately deviates from present day, in contrast to $\mathrm{EEM}_{\mathrm{r} 2}, \mathrm{EEM}_{\mathrm{r} 3}$, and $\mathrm{EEM}_{\mathrm{r} 4}$, which include substantial retreats of northwestern, southern, and northeastern Greenland, respectively. In all simulations, Greenland's main ice dome still persists with little change in surface elevation as this is implied by Eemian ice core data (e.g., NEEM community members 2013).

As counterpart to the interglacial experiments, we further study a number of glacial simulations. This set includes a classical LGM experiment with 21-ka boundary conditions (Table 1). As the name implies, the LGM represents the maximum glacial climate state of the last glacial cycle. Additionally, five time-slice simulations of MIS4, a less pronounced glacial state at $65 \mathrm{ka}$, are available. The MIS4 simulations differ with respect to the included NH ice sheets, so the sensitivity of the jet stream to the $\mathrm{NH}$ topography can be tested with all other external forcing held at the 65-ka level (Table 1). The different glacial topographies are displayed in Fig. 1b, sorted according to the height of the LIS. In all cases, the spatial extent of the ice sheets is as reconstructed for the LGM state (Peltier 2004), but the ice-sheet elevations are adjusted individually: (i) in MIS4 $4_{\text {lowLIS }}$ the LIS is set to $46 \%$ of the LGM height and to $100 \%$ elsewhere, (ii) in MIS $_{67}$ the LGM-size ice sheets are linearly scaled by $67 \%$, (iii) in MIS4 $4_{\text {lowFS }}$ the Fennoscandian ice sheet is set to $33 \%$ of its LGM height and $76 \%$ elsewhere, (iv) in MIS4 $_{\text {LGM }}$ full LGM ice sheets are applied, and (v) in MIS $_{125}$ the continental ice sheets are all scaled to $125 \%$ LGM height. Note that MIS $4_{125}$ has been conducted as a supplementary simulation for this study in order to test the possible behavior of a "superglacial" state in terms of ice-sheet height.

Moreover, two sensitivity simulations (not used in previous publications) are performed: $\mathrm{PI}_{\mathrm{LGM}}$ and $\mathrm{LGM}_{\mathrm{PD}}$. These simulations test the artificial cross combination of glacial and preindustrial conditions in terms of $\mathrm{NH}$ topography and the rest of the external forcing [i.e., orbital parameters, greenhouse gas (GHG) concentrations, prescribed SSTs, and sea ice]. This enables us to isolate the effect of the glacial ice sheets on one hand and the glacial external forcing on the other hand. In $\mathrm{PI}_{\mathrm{LGM}}$, full LGMsize ice sheets (Fig. 1b) are implemented within a preindustrial climate: that is, external forcing and lower boundary conditions are equivalent to PI1 (Table 1). Vice versa, in $\mathrm{LGM}_{\mathrm{PD}}$ the external forcing and lower boundaries are set to LGM levels but the present-day topography is used. Consequently, when comparing the full glacial conditions in LGM with the present-day/preindustrial climate, $\mathrm{LGM}_{\mathrm{PD}}$ and $\mathrm{PI}_{\mathrm{LGM}}$ can be used as effective intermediaries. On the contrary, the climate effect of the MIS4 glacial simulations cannot be disentangled with respect to the different boundary conditions (i.e., orbital, GHG, SSTs and sea ice, NH topography) as all of them are changed at the same time. As a consequence, the MIS4 simulations will only be compared among each other, which is useful to determine the sensitivity of the NA eddy-driven jet to the height of the LIS.

\section{b. Jet diagnostics}

Previous work has shown that the eddy-driven jet is best diagnosed from low-level winds (e.g., WO10; Barnes and Polvani 2013). Following WO10, we determine the NA eddy-driven jet as the maximum zonal mean zonal wind at low levels (averaged across 925$700 \mathrm{hPa}$ ) calculated for the NA domain of $15^{\circ}-75^{\circ} \mathrm{N}$, $60^{\circ} \mathrm{W}-0^{\circ}$. Besides the analysis of the winter mean jet, we diagnose the daily latitude of the NA eddy-driven jet (termed jet latitude index according to WO10) in order to study the intraseasonal jet variability. Time series of the daily jet latitude index are used to compute probability density functions (PDFs) employing the kernel method by Silverman (1981). Thereby, the standard smoothing parameter $h$ is set to $1.06 \sigma n^{-1 / 5}$, where $\sigma$ and $n$ denote the standard deviation and the sample size, respectively. The resulting jet latitude PDFs are a convenient measure to display the range and frequency of the latitudinal position of the NA eddy-driven jet. As a second method to determine intraseasonal jet variability, we apply an empirical orthogonal function (EOF) analysis to daily low-level zonal winds. Similar to the study by Eichelberger and Hartmann (2007), the EOF analysis provides us with the leading variability profiles in terms of jet speed and latitudinal position. Note that, for both analyses of daily jet variability, we use low-pass filtered wind data (using a 10-day Lanczos filter) in order to remove features related to individual synoptic systems.

\section{Representation of the NA eddy-driven jet in CCSM4}

The DJF mean low-level $(925-700 \mathrm{hPa})$ zonal wind averaged across $60^{\circ} \mathrm{W}-0^{\circ}$ provides the mean structure of the NA eddy-driven jet during winter (Fig. 2). In both ERA-Interim and the present-day model simulations (AMIP, PD1, and PD3) the climatological jet latitude (i.e., the latitude of maximum zonal wind speed) is approximately at $46^{\circ} \mathrm{N}$. However, the model simulations differ from ERA-Interim in terms of the mean jet speed. In ERA-Interim the jet speed is $\sim 10 \mathrm{~m} \mathrm{~s}^{-1}$ compared to 


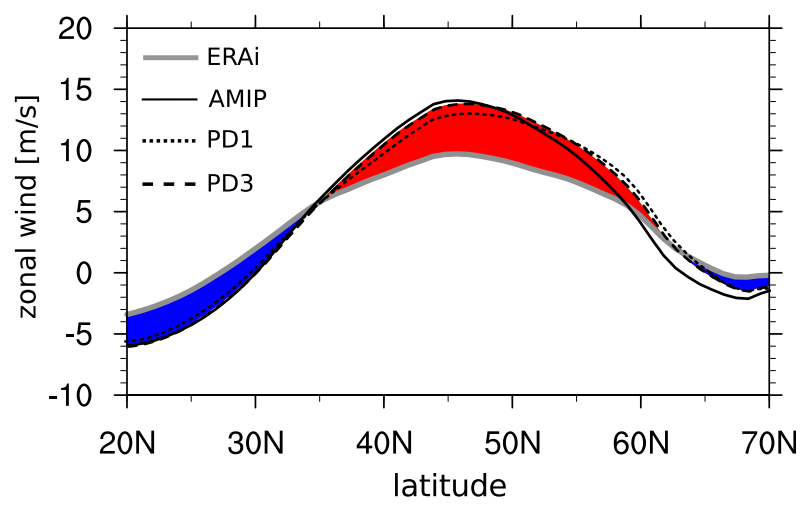

FIG. 2. DJF low-level $(925-700 \mathrm{hPa})$ zonal wind $\left(\mathrm{m} \mathrm{s}^{-1}\right)$ averaged across the NA domain $\left(60^{\circ} \mathrm{W}-0^{\circ}\right)$ in the AMIP, PD1, and PD3 simulations compared to ERA-Interim. The positive (negative) model bias for PD3 is shaded in red (blue).

$\sim 14 \mathrm{~m} \mathrm{~s}^{-1}$ in the model simulations. Moreover, the ERA-Interim zonal wind exhibits a rather broad structure without a distinct wind maximum. In contrast, all present-day simulations show a more peaked profile denoting a more clearly defined jet latitude compared to ERA-Interim. The distinct overestimation of the zonal wind speed in the central NA is likely connected to CCSM4's overestimation of wintertime planetary-scale stationary waves as shown by Shaw et al. (2014).

The jet stream bias is largely independent of the implemented lower boundary conditions. The AMIP simulation that uses observation-based SSTs and sea ice does not show an improved representation of the mean jet structure compared to PD1 and PD3 (Fig. 2), which are forced with CCSM3 SST and sea ice fields. In particular, the PD3 simulation is forced with lower boundary conditions that include a substantial bias in terms of surface conditions: for example, an overestimated winter sea ice cover and a too cold NA compared to the observation-based dataset by Hurrell et al. (2008) used in the AMIP simulation (not shown). However, this misrepresentation in surface conditions does not appear to be of importance for the NA jet structure. Instead, the model bias in all present-day simulations with respect to the ERA-Interim eddy-driven jet seems to be solely produced by the atmospheric model. This is in contrast to the results by Scaife et al. (2011), who showed that in the Hadley Centre climate model the representation of blockings in the Atlantic sector can be substantially improved when correcting the bias in the lower boundary conditions.

\section{NA eddy-driven jet in paleoclimate simulations}

The winter mean NA eddy-driven jet for all model simulations is shown in Fig. 3. Thereby, the simulations are grouped according to the climate states introduced in
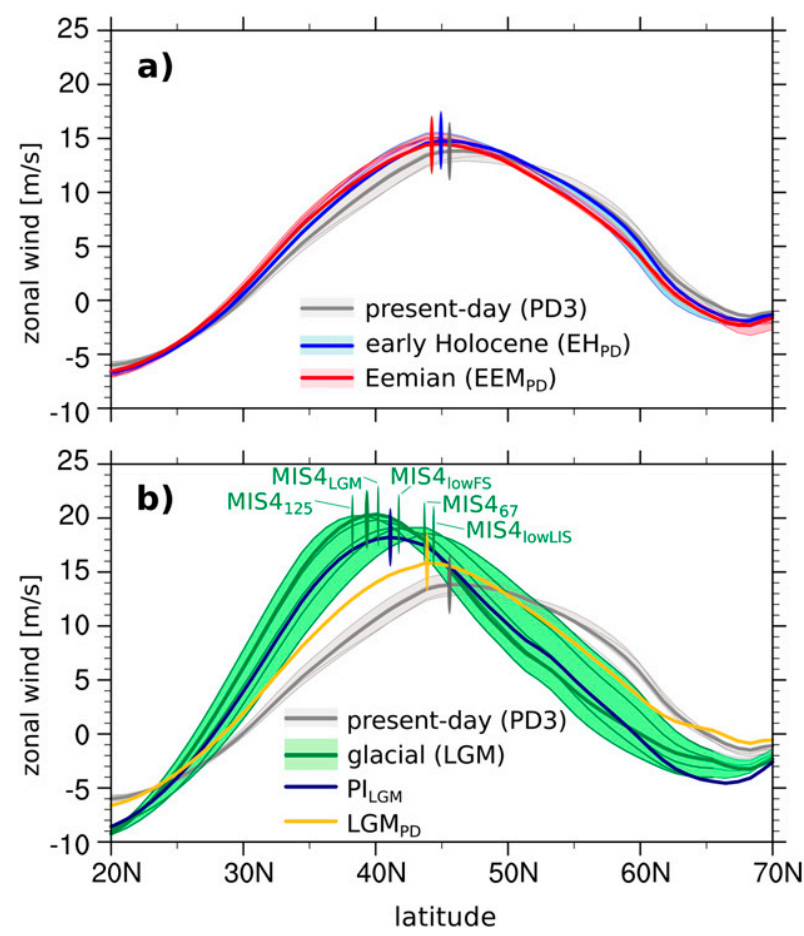

FIG. 3. DJF low-level $(925-700 \mathrm{hPa})$ zonal wind $\left(\mathrm{m} \mathrm{s}^{-1}\right)$ averaged across the NA domain $\left(60^{\circ} \mathrm{W}-0^{\circ}\right)$ in (a) interglacial and (b) glacial simulations. Shading denotes the spread among the simulations of the same group of experiments (listed in Table 1). For each group of experiments, one characteristic simulation is chosen (indicated as thick lines and denoted in brackets; e.g., PD3 for the present-day simulations). The respective latitude of maximum zonal wind (i.e., the jet latitude) is indicated by the vertical lines.

section 2a (Table 1). Each simulation is indicated by an individual line whereas the range within a state is represented by the shading. For each of the four paleoclimate states (i.e., present day, early Holocene, Eemian, and glacial), one characteristic simulation is selected (indicated by the thick line and denoted in the legend in brackets) that will be used in the following analysis as representative for the corresponding climate state.

During past interglacial conditions (Fig. 3a) the mean winter jet is comparable to present-day conditions. For both the early Holocene and Eemian simulations, we find a slight strengthening and southward shift compared to present day. Moreover, the shift seems related to the orbital forcing but is irrespective of the implemented icesheet topography as the different $\mathrm{NH}$ ice sheets used in the early Holocene and Eemian simulations (Fig. 1a) do not substantially change the mean winter jet. Indeed, the ranges of the early Holocene and the Eemian simulations are comparable to the range spanned by the present-day and preindustrial simulations, respectively.

In contrast to the interglacial experiments, all glacial simulations show a distinct southward shift and a 
a) present-day (PD3)

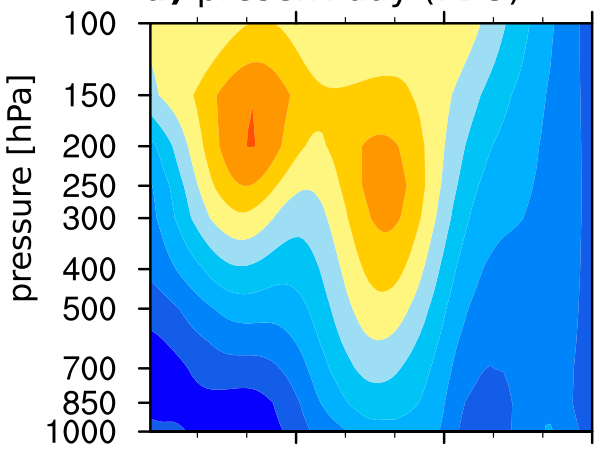

d) glacial (LGM)

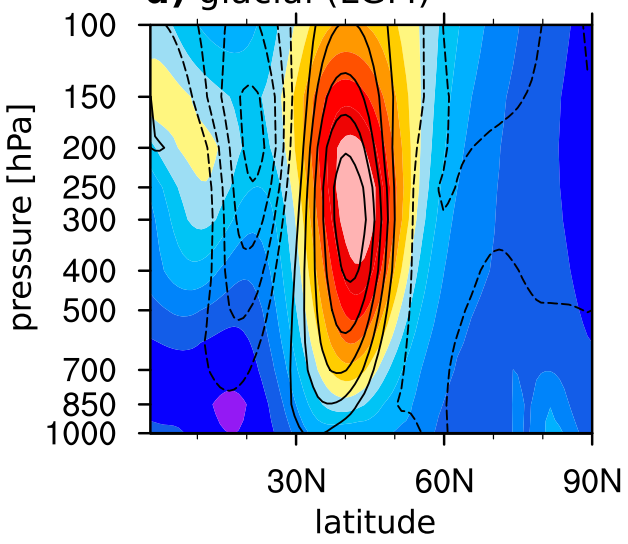

b) early Holocene (EHpd)

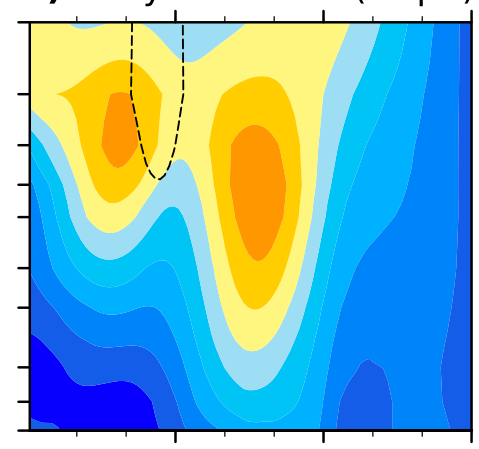

e) $\mathrm{PI}_{\mathrm{LGM}}$

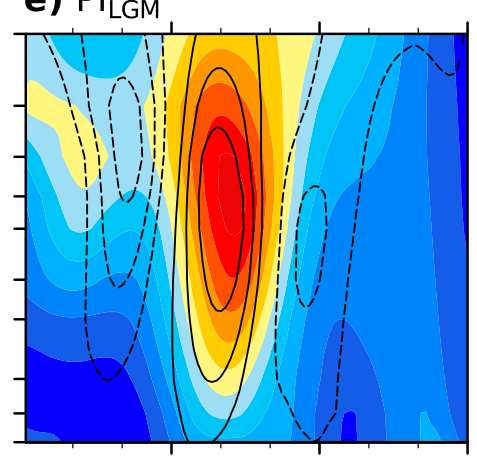

$30 \mathrm{~N} \quad 60 \mathrm{~N}$

latitude c) Eemian (EEMpd)

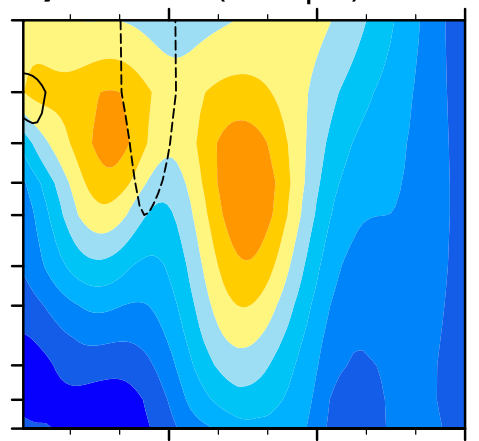

f) $L G M_{P D}$

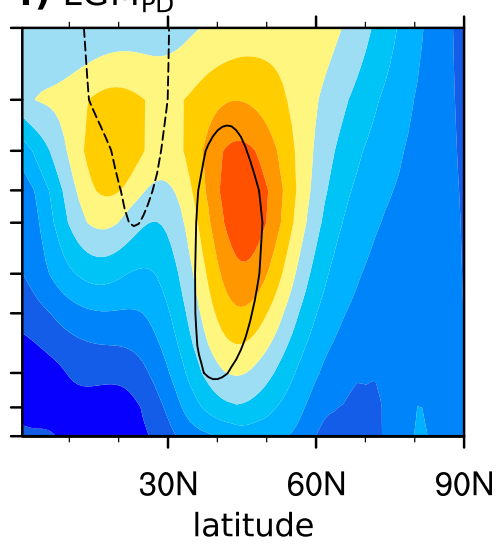

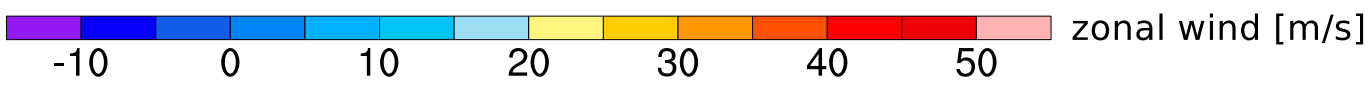

FIG. 4. DJF zonal wind $\left(\mathrm{m} \mathrm{s}^{-1}\right)$ averaged across the NA domain $\left(60^{\circ} \mathrm{W}-0^{\circ}\right)$ for (a) present day (PD3), (b) early Holocene (EH $\left.\mathrm{PD}\right)$, (c) Eemian $\left(\mathrm{EEM}_{\mathrm{PD}}\right),(\mathrm{d})$ glacials $(\mathrm{LGM}),(\mathrm{e}) \mathrm{PI}_{\mathrm{LGM}}$, and (f) $\mathrm{LGM}_{\mathrm{PD}}$. Shading denotes the climatological mean of the corresponding simulation and contour lines show the deviation from present day. The contour-level spacing is $5 \mathrm{~m} \mathrm{~s}^{-1}$, with negative contour lines dashed and the zero line omitted. All anomalies shown are significant at the $5 \%$ level based on $t$ test statistics.

substantial enhancement of the jet speed compared to present-day conditions (Fig. 3b). Moreover, the glacial winter mean zonal wind profiles also include more clearly defined wind maxima. In general, we find that the stronger the southward shift of the jet, the higher the jet speed and the sharper the peak in the low-level zonal wind profile. Within the set of MIS4 simulations, the strength of the southward shift largely depends on the height of the LIS. Hence, the magnitude of the southward shift increases monotonically with the implemented LIS height, so the maximum displacement is found for MIS4 $4_{125}$, which incorporates the highest LIS, whereas the minimum dis-

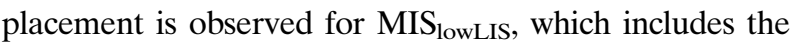
lowest LIS (Fig. 1b).

The dominant influence of the LGM-size ice sheets is also evident when comparing the two sensitivity experiments: $\mathrm{PI}_{\mathrm{LGM}}$ and $\mathrm{LGM}_{\mathrm{PD}}$ (Fig. 3b). The jet profile of $\mathrm{PI}_{\mathrm{LGM}}$ largely lies within the range of the glacial simulations, whereas the $\mathrm{LGM}_{\mathrm{PD}}$ jet shows a rather moderate southward shift as well as a moderate enhancement of the jet speed with respect to present day. $\mathrm{LGM}_{\mathrm{PD}}$, thus, represents an intermediate state between the group of interglacial and glacial simulations. The $\mathrm{PI}_{\mathrm{LGM}}$ jet profile, however, emphasizes that glacial boundary conditions in terms of GHGs, insolation, SSTs, and sea ice are not needed to establish the glacial characteristics of the NA eddy-driven jet; the physical presence of the large LIS is

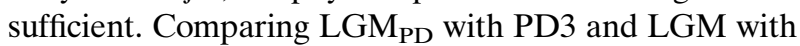
$\mathrm{PI}_{\mathrm{LGM}}$ (Fig. 3b) shows a similar response of the nontopographic glacial boundary conditions (i.e., a moderate southward shift and acceleration of the jet), regardless of the implemented ice sheet. Hence, the effects of the icesheet topography and of the rest of the glacial external forcing seem to be rather independent in nature.

The vertical profile of the winter mean NA zonal winds (Fig. 4) reveals that the observed changes in the NA jet stream at low levels (Fig. 3) are also associated with changes in the high-level winds. For present-day 
climate conditions, the NA zonal wind field shows two equally strong wind maxima: that is, the subtropical jet centered around $20^{\circ} \mathrm{N}$ restricted to high levels (maximum at $\sim 200 \mathrm{hPa}$ ) and the eddy-driven jet placed at $45^{\circ} \mathrm{N}$ extending from high levels down to the surface (Fig. 4a). This jet structure is also found in all other interglacial simulations (e.g., $\mathrm{EH}_{\mathrm{PD}}$ and $\mathrm{EEM}_{\mathrm{PD}}$; Figs. 4b,c), confirming that the NA zonal winds are robust at all levels against the anomalous interglacial forcing tested here. Still, some significant but minor deviations from the present-day state can be found: for example, a slight weakening of the subtropical jet at its northern flank apparent in both $\mathrm{EH}_{\mathrm{PD}}$ and $\mathrm{EEM}_{\mathrm{PD}}$ (Figs. 4b,c), likely caused by the corresponding orbital forcing.

On the contrary, the glacial simulations (e.g., LGM; Fig. 4d) show a fundamentally different NA zonal wind structure during winter. The glacial NA subtropical jet is substantially weaker and shifted equatorward. The eddydriven jet is shifted southward as well but experiences a clear acceleration of its speed across all levels. Consequently, the eddy-driven jet becomes the dominant zonal wind feature in the NA domain under glacial climate conditions. The zonal wind velocities in the glacial eddydriven jet core exceed $50 \mathrm{~m} \mathrm{~s}^{-1}$, compared to maximum zonal wind speeds of $\sim 30 \mathrm{~m} \mathrm{~s}^{-1}$ apparent in both branches of the interglacial NA jet (Figs. $4 a-c$ ). Furthermore, the sensitivity simulations again demonstrate the dominant role of glacial topography, with $\mathrm{PI}_{\mathrm{LGM}}$ showing the glacial jet structure (Fig. 4e), whereas the interglacial jet behavior mostly remains in $\mathrm{LGM}_{\mathrm{PD}}$ (Fig. 4f). As previously observed at low levels, the nontopographic glacial boundary conditions in $\mathrm{LGM}_{\mathrm{PD}}$ lead to an enhancement of the eddy-driven jet on its southward flank (Fig. 4f), thus moderately shifting the NA eddy-driven jet latitude southward compared to present day (Fig. 3b). The comparison of LGM and $\mathrm{PI}_{\text {LGM }}$ (Figs. 4d,e) further confirms that the LGM topography is not enough to fully produce the LGM-like anomalies. Instead, other glacial forcing and boundary conditions (i.e., lowered GHG conditions, colder SSTs, and expanded sea ice) contribute to the southward shift and acceleration of the glacial eddy-driven jet. However, the primary driver is the presence of glacial-size ice sheets.

\section{Mechanisms behind glacial-interglacial jet changes}

The strong westerly winds extending throughout the midlatitudinal troposphere can only be sustained against drag by eddy momentum fluxes (Hartmann 2007). Consequently, the glacial-interglacial changes in the NA zonal winds (and the jet) observed in Figs. 3 and 4 must be linked to concurrent changes in the stationary wave and/or transient eddy activity.

\section{a. Role of stationary waves}

Stationary waves (or stationary eddies) emerge as zonal asymmetries in the time mean flow related to stationary Rossby waves that are triggered by zonal asymmetries in the lower boundary conditions: namely, topography or diabatic heating (e.g., Held et al. 2002; Brayshaw et al. 2009). For the NH, the Rocky Mountains have been identified as the main topographic feature influencing the present-day stationary wave pattern (Fig. 5a). Thereby, anticyclonic flow is generated over the poleward part of the Rocky Mountains, where the flow predominantly passes over the mountain ridge, whereas a stationary cyclone is created on the equatorward section, where the flow is partially blocked or deflected around the orographic barrier. This disturbance from the zonal flow further produces distinct stationary eddies downstream (e.g., anticyclonic flow over the NA and cyclonic flow over the subtropical Atlantic). This present-day stationary wave pattern is apparent in all interglacial simulations (e.g., $\mathrm{EH}_{\mathrm{PD}}$ and $\mathrm{EEM}_{\mathrm{PD}}$; Figs. 5b,c), and the moderate interglacial changes in the high-latitude topography (around Hudson Bay and Greenland) are found to be of minor importance.

In contrast, the presence of LGM-size continental ice sheets strongly influences the stationary wave pattern as seen for LGM and $\mathrm{PI}_{\mathrm{LGM}}$ (Figs. 5d,e). The LIS amplifies the Rocky Mountains' effect as it increases the height and eastward extension of the dominant topographic feature of the North American continent. As a consequence, the stationary wave pattern is both strengthened and shifted to the southeast in areas located downstream of the LIS (i.e., over the NA and Europe). The MIS4 sensitivity simulations confirm that the higher the LIS, the stronger the change in the stationary wave pattern (not shown). Hence, they possibly explain the aforementioned dependence of the NA jet structure on the size of the LIS. Besides, the glacial nontopographic boundary conditions implemented in $\mathrm{LGM}_{\mathrm{PD}}$ have a much weaker effect on the $\mathrm{NH}$ stationary wave pattern (Fig. 5f).

\section{b. Role of transient eddies}

Besides the influence of the stationary waves, the interaction between transient eddies and the mean flow is an important process that provides energy to the NA eddy-driven jet. The eddy activity can be measured as the 2.5-6-day bandpass filtered (Blackmon 1976) transient eddy kinetic energy (TEKE; TEKE $=0.5\left(\overline{u^{\prime 2}+v^{2}}\right)$; Fig. 6). The filtering isolates the eddy activity associated with baroclinic waves (i.e., synoptic systems) and 
a) present-day (PD3)

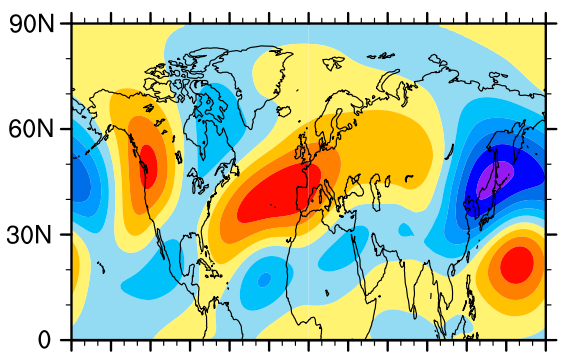

d) glacial (LGM)

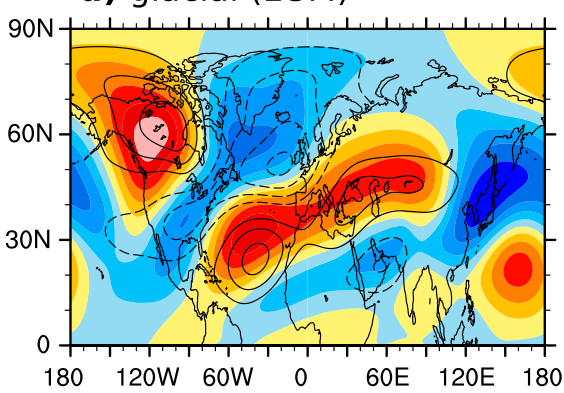

b) early Holocene ( $E \mathrm{H}_{\mathrm{PD}}$ )

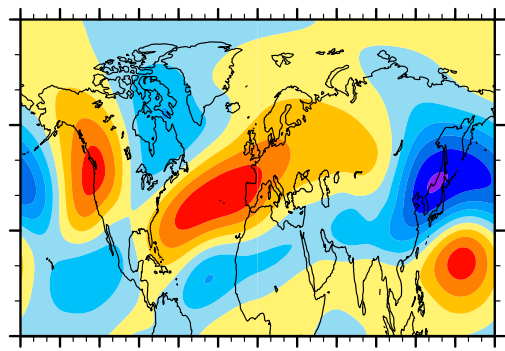

c) Eemian (EEM $\left.M_{P D}\right)$

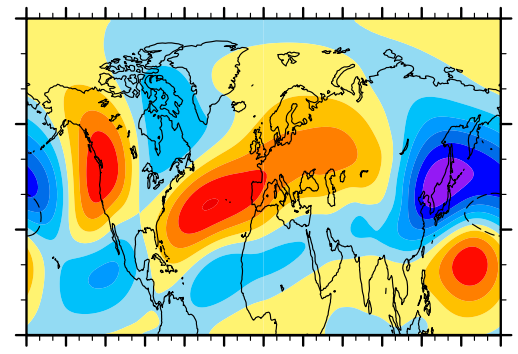

e) $\mathrm{PI}_{\text {LGM }}$

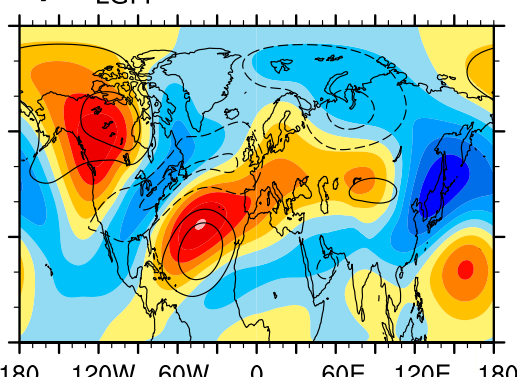

f) $L G M_{P D}$

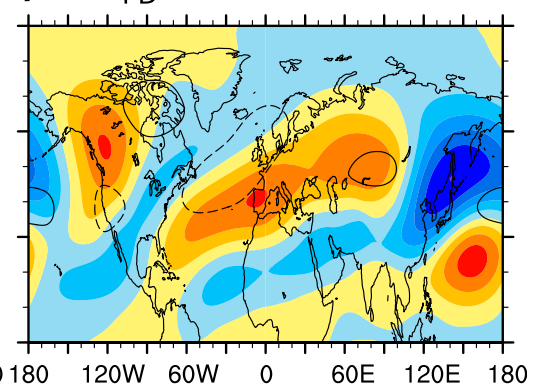

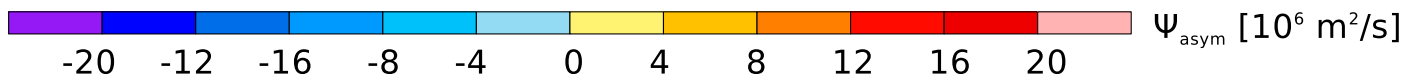

FIG. 5. DJF zonally asymmetric component of the 500-hPa streamfunction $\left(10^{6} \mathrm{~m}^{2} \mathrm{~s}^{-1}\right)$ for (a) present day (PD3), (b) early Holocene $\left(\mathrm{EH}_{\mathrm{PD}}\right)$, (c) Eemian $\left(\mathrm{EEM}_{\mathrm{PD}}\right)$, (d) glacials (LGM), (e) $\mathrm{PI}_{\mathrm{LGM}}$ and (f) $\mathrm{LGM}_{\mathrm{PD}}$. Shading denotes the climatological mean of the corresponding simulation and contour lines show the deviation from present day. The contour-level spacing is $4\left(10^{6} \mathrm{~m}^{2} \mathrm{~s}^{-1}\right)$, negative anomalies are dashed, and the zero line is omitted.

provides a scale separation from low-frequency eddies that may reflect the jet variability itself.

For all interglacial simulations (Figs. 6a-c), we find distinct eddy activity associated with synoptic systems over the NA midlatitudes termed the NA storm track. The maximum eddy activity is located near Newfoundland and overlaps with the strongest zonal winds of the interglacial eddy-driven jet (Fig. 6a). In a glacial climate (e.g., LGM; Fig. 6d), the eddy activity is reduced in regions north of $\sim 50^{\circ} \mathrm{N}$ while it is enhanced in the midlatitudinal band of $30^{\circ}-50^{\circ} \mathrm{N}$. Additionally, the maximum in TEKE is shifted toward the eastern NA. Interestingly, these glacial-interglacial changes seem to be caused by both the LGM-state topography and nontopographic boundary conditions, as illustrated by the two sensitivity simulations $\mathrm{PI}_{\mathrm{LGM}}$ and $\mathrm{LGM}_{\mathrm{PD}}$ (Figs. 6e,f). The decrease in eddy activity north of $\sim 50^{\circ} \mathrm{N}$ and the resulting narrowing of the NA storm track are found in LGM and $\mathrm{PI}_{\mathrm{LGM}}$ and therefore related to the presence of the LIS. As seen in Fig. 5e, the LIS exerts a substantial strengthening of the stationary wave pattern causing a southeastern shift (through a clockwise rotation) of the NA flow and this displacement seems to hold as well for the synoptic-scale eddies. However, the comparison of the
TEKE anomalies in LGM and $\mathrm{PI}_{\mathrm{LGM}}$ reveals that the presence of the LIS cannot explain the full magnitude of the glacial-interglacial difference in eddy activity. The glacial SSTs and GHG concentrations in LGM $_{P D}$ further foster the generation of eddies over the midlatitude Atlantic. In contrast to $\mathrm{PI}_{\mathrm{LGM}}$ the anomalous eddy activity in $\mathrm{LGM}_{\mathrm{PD}}$ is unlikely linked to changes in the $\mathrm{NH}$ stationary waves but rather explained by the increased temperature gradients (i.e., increased baroclinicity) over the midlatitudinal NA resulting from the glacial boundary conditions (not shown).

For the purpose of linking the changes in the NA synoptic eddy activity and the concurrent changes in the NA eddy-driven jet, the so-called barotropic production $\mathbf{E}_{h} \cdot \mathbf{D}$ (Mak and Cai 1989) is a useful measure as it describes the transformation of eddy kinetic energy between the eddies and the mean flow. Thereby, $\mathbf{E}_{h}=\left[(1 / 2)\left(\overline{v^{\prime 2}}-\overline{u^{\prime 2}}\right),-\overline{u^{\prime} v^{\prime}}\right]$ represents the horizontal components of the $\mathbf{E}$ vector (Hoskins et al. 1983) in the form used by Trenberth $(1986)$ and $\mathbf{D}=[(\delta \bar{u} / \delta \bar{x})-(\delta \bar{v} / \delta \bar{y}),(\delta \bar{v} / \delta \bar{x})+(\delta \bar{u} / \delta \bar{y})]$ corresponds to the deformation vector of the mean flow, which consists of horizontal stretching and shearing.

At present, $\mathbf{E}_{h} \cdot \mathbf{D}$ is positive near Newfoundland, indicating that transient eddies gain kinetic energy from 
a) present-day (PD3)

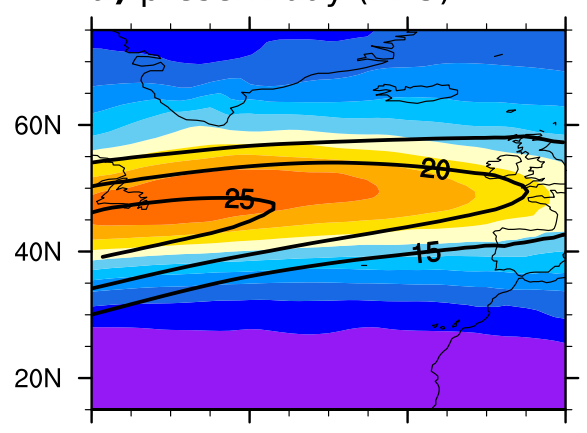

\section{d) glacial (LGM)}

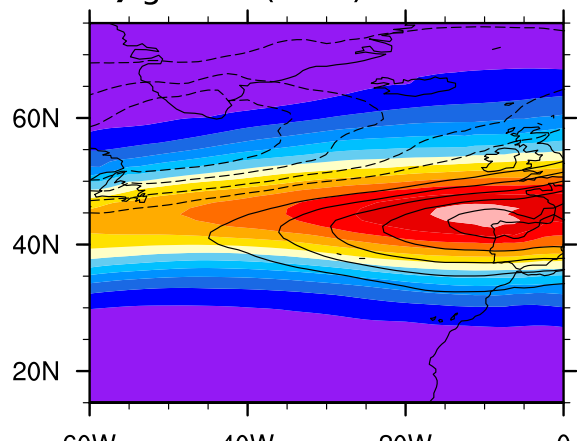

$60 \mathrm{~W}$ b) early Holocene (EHPD)

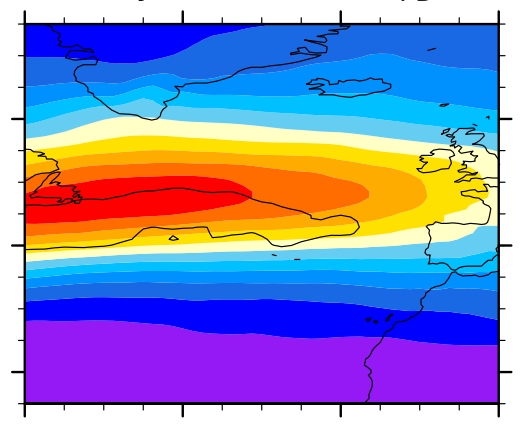

e) $\mathrm{Pl}_{\mathrm{LGM}}$

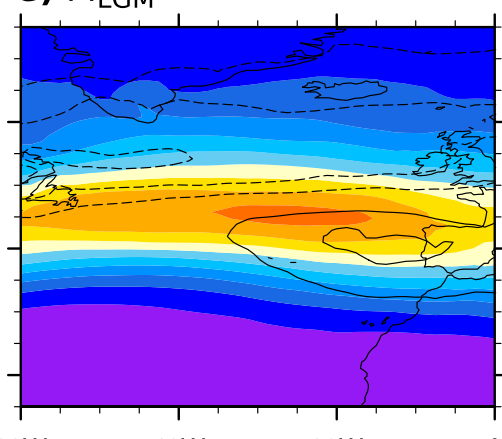

c) Eemian (EEMPD)

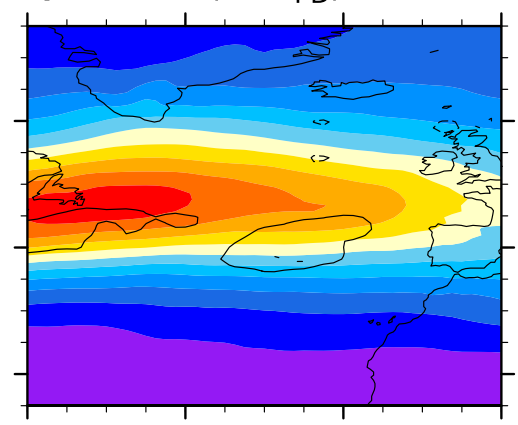

f) $L G M_{P D}$

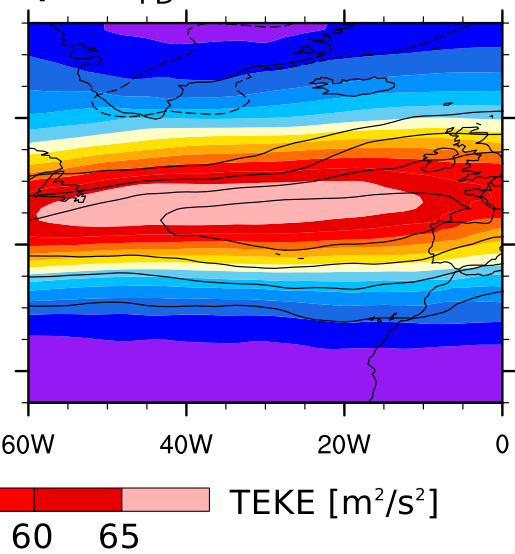

\section{$\begin{array}{llllllllllll}10 & 15 & 20 & 25 & 30 & 35 & 40 & 45 & 50 & 55 & 60 & 65\end{array}$}

FIG. 6. DJF mean TEKE $\left(\mathrm{m}^{2} \mathrm{~s}^{-2}\right)$ using 500-hPa 2.5-6-day bandpass filtered winds for (a) present day (PD3), (b) early Holocene $\left(\mathrm{EH}_{\mathrm{PD}}\right)$, (c) Eemian $\left(\mathrm{EEM}_{\mathrm{PD}}\right)$, (d) glacials (LGM), (e) $\mathrm{PI}_{\mathrm{LGM}}$, and (f) $\mathrm{LGM}_{\mathrm{PD}}$. Shading denotes the climatological mean of the corresponding simulation and contour lines show the deviation from present day. The contour-level spacing is $5 \mathrm{~m}^{2} \mathrm{~s}^{-2}$, negative anomalies are dashed, and the zero line is omitted. The thick contour lines in (a) indicate the DJF mean zonal wind at $500 \mathrm{hPa}$ for present day (PD3) with contours every $5 \mathrm{~m} \mathrm{~s}^{-1}$ starting at $15 \mathrm{~m} \mathrm{~s}^{-1}$.

the mean flow in this region. Furthermore, the presentday $\mathbf{E}_{h} \cdot \mathbf{D}$ is negative over the central NA, demonstrating that the transient eddies lose energy to the mean flow near the southern flank of the NA eddy-driven jet (Fig. 7a). The present-day $\mathbf{E}_{h} \cdot \mathbf{D}$ pattern remains essentially unchanged for all other interglacial settings tested with the set of early Holocene and Eemian simulations (shown for $\mathrm{EH}_{\mathrm{PD}}$ and $\mathrm{EEM}_{\mathrm{PD}}$ in Figs. 7b,c).

On the contrary, the glacial simulations feature distinct differences in the $\mathbf{E}_{h} \cdot \mathbf{D}$ pattern compared to the interglacial state (Fig. 7d-f). Both the area where eddies receive energy from the mean flow and the region where synoptic eddies provide momentum to the mean flow are shifted southeastward in LGM and $\mathrm{PI}_{\mathrm{LGM}}$. Hence, the area of barotropic production lies over the central NA whereas the eddy-driven jet is accelerated by the synoptic eddies near the Iberian peninsula. In $\mathrm{LGM}_{\mathrm{PD}}$, we find a general southward shift as well as an enhancement of the present-day $\mathbf{E}_{h} \cdot \mathbf{D}$ pattern (Fig. 7f). Comparing $\mathrm{LGM}_{\mathrm{PD}}$ with $\mathrm{PI}_{\mathrm{LGM}}$ the glacial nontopographic forcing seems to be at least as efficient in modifying the transient eddy-mean flow interactions as the presence of glacial ice sheets.

\section{c. Are stationary or transient eddies more important?}

The effect of stationary waves and synoptic eddies on the mean flow can be further analyzed by the stationary and transient eddy momentum flux convergence (MFC; Fig. 8). For the NA sector, the zonal and meridional stationary eddy flux of zonal momentum is important (Figs. 8a,b) as well as the meridional flux associated with transient eddies (Fig. 8c). In contrast, the zonal transient eddy flux of zonal momentum is negligible (not shown). In all interglacial simulations (including present day), we find that the meridional and zonal component of the stationary MFC (Figs. 8a,b) partly compensate each other but overall result in a net MFC surplus of up to $2 \times$ $10^{-5} \mathrm{~m} \mathrm{~s}^{-2}$ around $45^{\circ}-60^{\circ} \mathrm{N}$ (not shown). In addition, the transient eddies under interglacial climate conditions accelerate the NA mean flow in the latitudinal 
a) present-day (PD3)

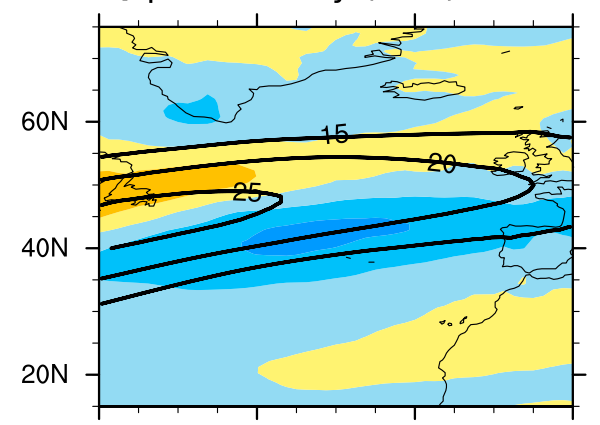

d) glacial (LGM)

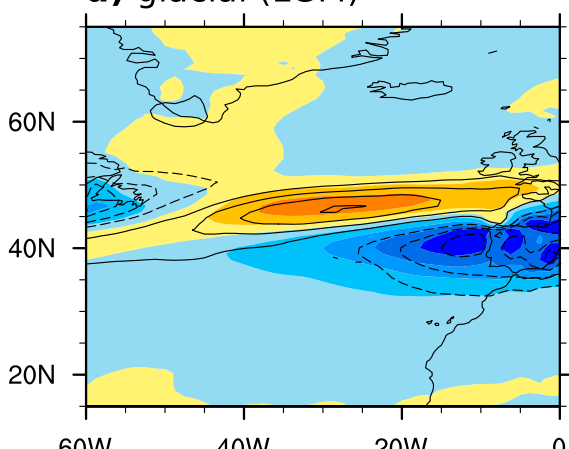

$60 \mathrm{~W}$ b) early Holocene (EHPD)

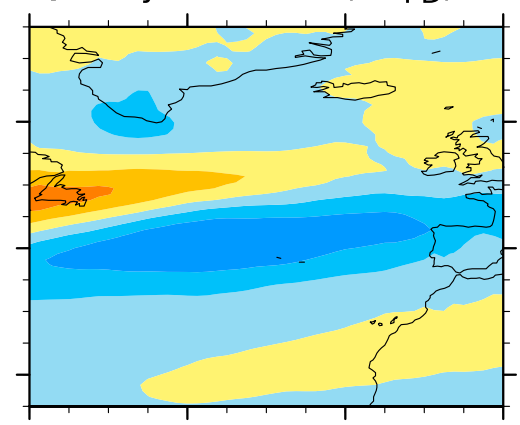

e) $\mathrm{PI}_{\mathrm{LGM}}$

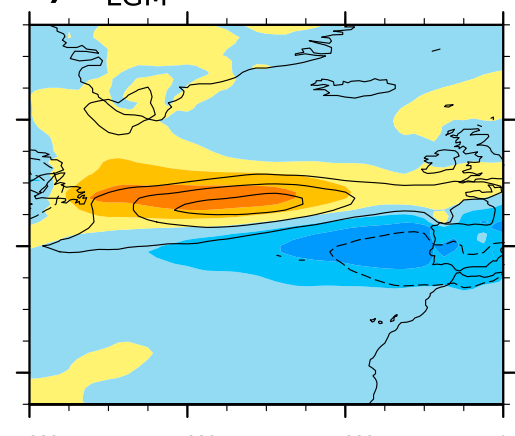

\section{c) Eemian (EEMPD)}

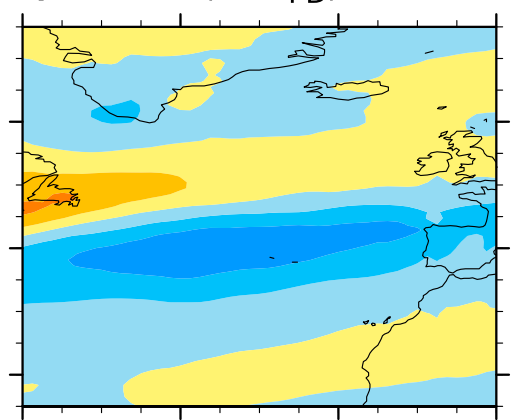

f) $L G M P D$

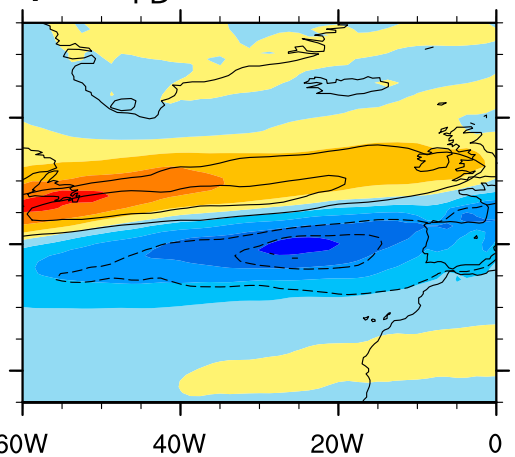

\section{$\begin{array}{lllllllllll}-0.4 & -0.32 & -0.24 & -0.16 & -0.08 & 0 & 0.08 & 0.16 & 0.24 & 0.32 & 0.4\end{array}$}

$\mathbf{E}_{\mathrm{h}} \cdot \mathbf{D}\left[\mathrm{m}^{2} / \mathrm{s}^{3}\right]$

FIG. 7. DJF barotropic production $\mathbf{E}_{h} \cdot \mathbf{D}$ of 500-hPa 2.5-6-day bandpass filtered winds for (a) present day (PD3), (b) early Holocene $\left(\mathrm{EH}_{\mathrm{PD}}\right)$, (c) Eemian $\left(\mathrm{EEM}_{\mathrm{PD}}\right)$, (d) glacials (LGM), (e) $\mathrm{PI}_{\mathrm{LGM}}$, and (f) $\mathrm{LGM}_{\mathrm{PD}}$. Shading denotes the climatological mean of the corresponding simulation, and contour lines in (b)-(f) show the deviation from present day. The contour-level spacing is $0.08 \mathrm{~m}^{2} \mathrm{~s}^{-3}$, negative anomalies are dashed, and the zero line is omitted. Positive (negative) values indicate areas where eddies gain (lose) momentum from (to) the mean flow. The thick contour lines in (a) indicate the DJF mean zonal wind at $500 \mathrm{hPa}$ for present day (PD3) with contours every $5 \mathrm{~m} \mathrm{~s}^{-1}$ starting at $15 \mathrm{~m} \mathrm{~s}^{-1}$.

band of $35^{\circ}-60^{\circ} \mathrm{N}$ through positive MFC of up to $2 \times$ $10^{-5} \mathrm{~m} \mathrm{~s}^{-2}$ (Fig. 8c) and, hence, the stationary and transient MFCs are of similar magnitude.

For LGM and $\mathrm{PI}_{\mathrm{GM}}$, we find a substantial strengthening and a southward shift in both components of the stationary MFC compared to the interglacial simulations (Figs. 8a,b) and also compared to $\mathrm{LGM}_{\mathrm{PD}}$. In addition, $\mathrm{LGM}$ and $\mathrm{PI}_{\mathrm{LGM}}$ show a reduction in transient eddy MFC north of $40^{\circ} \mathrm{N}$ and an increase around $35^{\circ} \mathrm{N}$ in agreement with the previously diagnosed anomalies in $\mathbf{E}_{h} \cdot \mathbf{D}$ (Figs. 7d,e). However, the magnitudes of the glacial-interglacial changes in stationary MFC clearly exceed the respective changes in transient MFC. This suggests that the glacial NA eddy-driven jet is primarily accelerated by the anomalous stationary wave activity triggered by the glacial topography.

In contrast, the nontopographic glacial forcing in $\mathrm{LGM}_{\mathrm{PD}}$ results in a minor southward shift and rather a weakening in the stationary MFC compared to present day (Figs. 8a,b). Consequently, the moderate strengthening and southward shift of the NA eddy-driven jet in $\operatorname{LGM}_{\mathrm{PD}}$ (e.g., Fig. 4f) is more likely connected with the increase in transient MFC south of $\sim 40^{\circ} \mathrm{N}$ (Fig. 8c), which, however, is not very distinct either. Nevertheless, the MFC analysis confirms that the sensitivity of the NA eddy-driven jet (presented in Figs. 4 and 3) relates to respective changes in both stationary and transient eddy momentum flux and their convergences.

\section{NA eddy-driven jet variability in present and past climate}

Previous work has shown that the NA eddy-driven jet is very variable on daily time scales, particularly with respect to its latitudinal position (e.g., WO10). As a consequence, a thorough analysis of the jet stream for different climate states should not be limited to seasonal mean changes. In the following section, we investigate 
a) stationary eddy meridional flux convergence

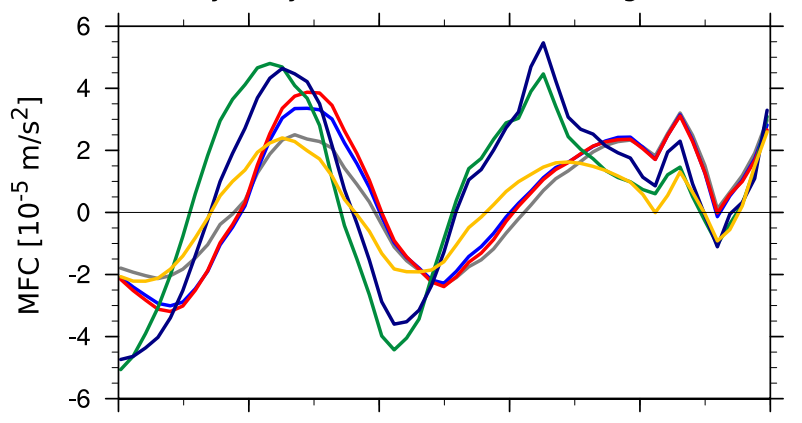

b) stationary eddy zonal flux convergence

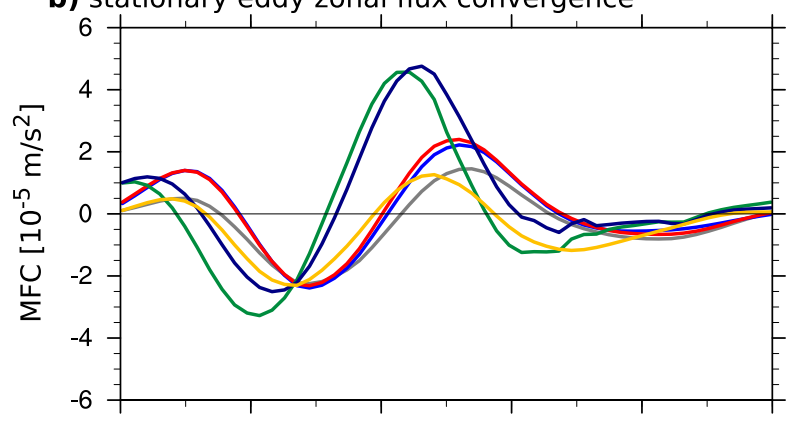

c) transient eddy meridional flux convergence

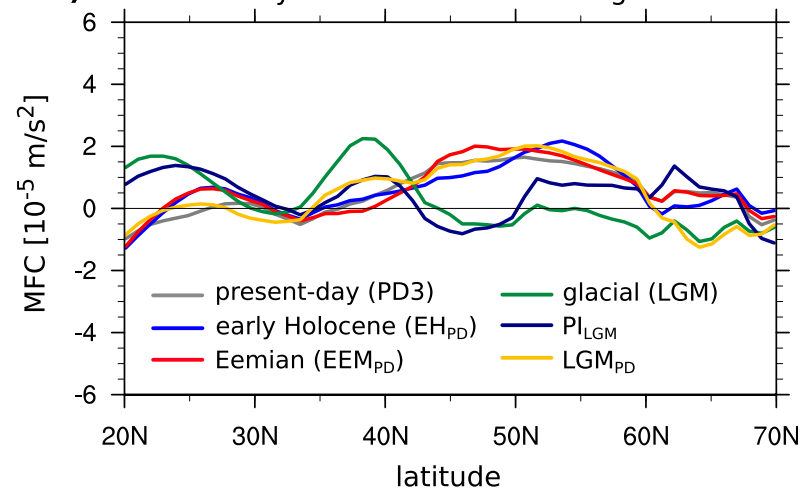

FIG. 8. DJF 250-850-hPa zonal MFC $\left(\mathrm{m} \mathrm{s}^{-2}\right)$ across the NA domain $\left(60^{\circ} \mathrm{W}-0^{\circ}\right)$ by (a) stationary eddies (meridional flux), (b) stationary eddies (zonal flux), and (c) transient eddies (meridional flux).

the glacial and interglacial character in terms of daily winter jet variability using the jet latitude index and the EOF analysis as two independent tools (see section $2 b$ for details).

\section{a. Representation of the jet latitude index in CCSM4}

The jet latitude index calculated with the WO10 algorithm determines the daily latitudinal position of the NA eddy-driven jet through the diagnosis of the position of the maximum zonal mean zonal wind. Based on the PDFs of the jet latitude index time series, the daily variability of the NA eddy-driven jet in terms of latitudinal shifts can be illustrated (using a kernel fit for the smoothing; Fig. 9a). The PDF for ERA-Interim (gray line in Fig. 9a) shows the trimodal distribution of the NA eddy-driven jet latitude previously found in WO10. However, the three present-day simulations-namely, AMIP, PD1, and PD3 (black lines in Fig. 9a) - do not reproduce the trimodal structure. The model simulations rather show unimodal profiles with a high frequency of the jet being located around the central position $\left(\sim 45^{\circ} \mathrm{N}\right)$. This is similar to many other climate models of the CMIP3 archive, which all fail to simulate the observed trimodal distribution (Hannachi et al. 2013). Additionally, our CCSM4 present-day simulations generally underestimate the jet latitude variability as the respective PDFs indicate a range from around $35^{\circ}$ to $60^{\circ} \mathrm{N}$ in contrast to $30^{\circ}-65^{\circ} \mathrm{N}$ in ERA-Interim (Fig. 9a). The overestimation of the central jet regime occurrence and the unimodal structure are rather independent of the lower boundary conditions. The AMIP simulation being forced with lower boundary conditions obtained from reanalyses (i.e., the best possible lower boundaries) even shows the strongest deviation from ERA-Interim.

The cause for the model's inability in reproducing the trimodality is likely an overestimation of the zonal wind speed around $45^{\circ} \mathrm{N}$, holding the NA jet in its central position. This goes in hand with the winter mean zonal wind (Fig. 2), which shows that the model exhibits a distinct overestimation in zonal wind speed in the area of the central jet position $\left(\sim 45^{\circ} \mathrm{N}\right)$. As the WO10 algorithm diagnoses the jet latitude by identifying the position of the maximum zonal wind, the latitudinal variability is directly connected with the jet speed. As a consequence, the winter mean bias in the zonal wind speed (Fig. 2) can perturb the model's daily jet latitude index and therefore the respective jet latitude PDFs (shown in Fig. 9a) do not necessarily portray the jet latitude variability in a correct way. Hence, it is reasonable to consider a slightly different approach to detect the jet latitude within the model simulations. Consequently, we use bias-corrected daily wind data for the jet latitude algorithm by WO10: that is, the climatological zonal wind bias (shown for PD3 as shaded area in Fig. 2) is removed beforehand from the daily zonal wind fields. This means that for each day the zonal wind is artificially reduced in the central NA latitudes (between $35^{\circ}$ and $60^{\circ} \mathrm{N}$; blue shading in Fig. 2) and increased at polar $\left(>60^{\circ} \mathrm{N}\right)$ and subtropical $\left(<35^{\circ} \mathrm{N}\right)$ latitudes (red shading in Fig. 2). Note that, although the model's representation of the jet is clearly modified by this approach, the model's daily jet variability should not be disturbed as every day is treated in the same way.

Estimating the PDFs of the jet latitude index after correcting for the climatological zonal wind bias shows 
a) original WO10 algorithm

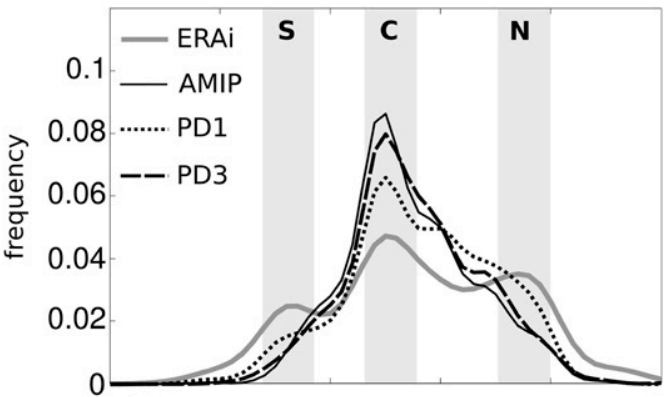

b) including bias correction

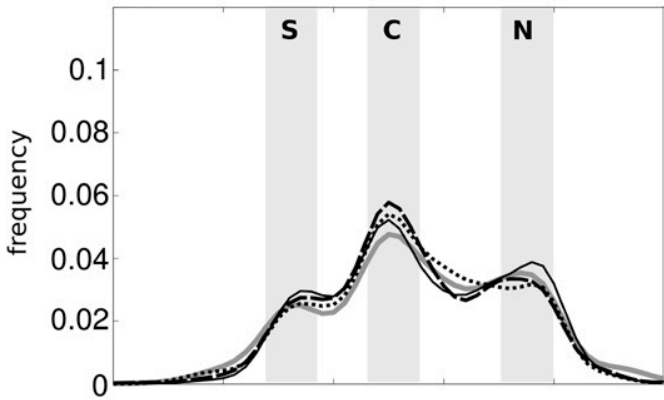

c) effect of the bias correction: b) - a)

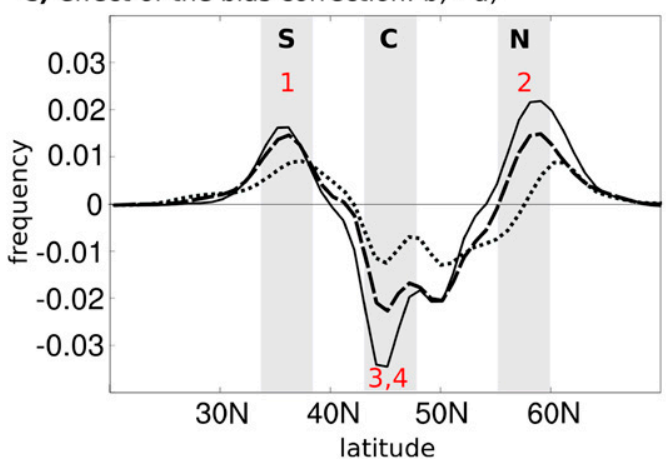

d) z500 composites associated with jet regimes
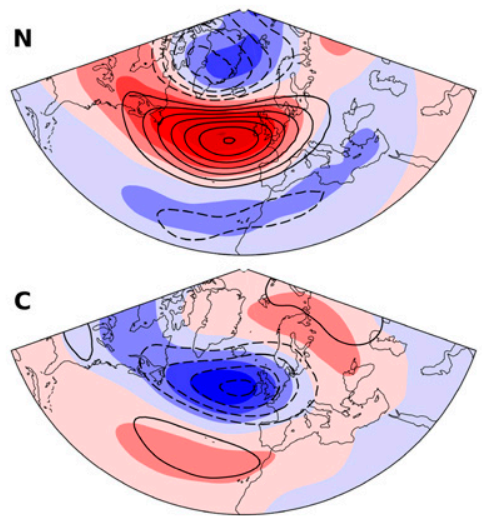

$\mathbf{S}$

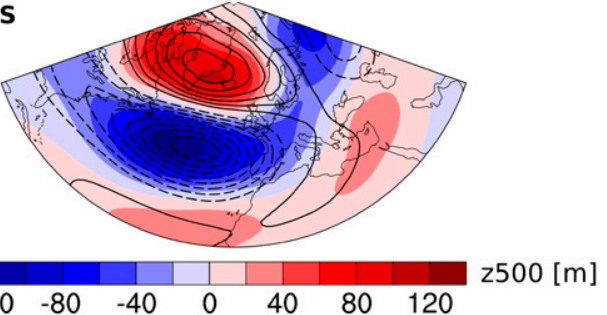

e) z500 composites associated with c)

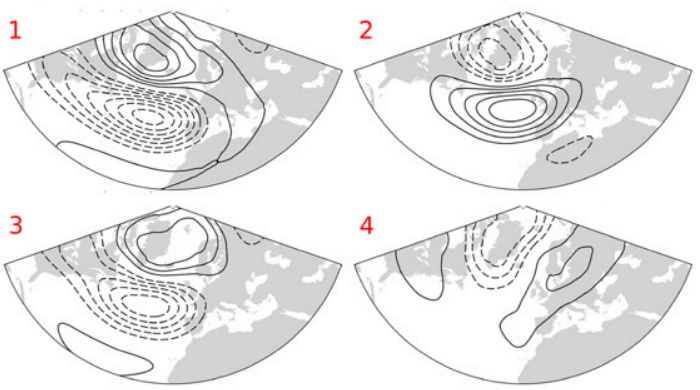

FIG. 9. PDFs of daily DJF jet latitude for ERA-Interim and the AMIP, PD3, and PD1 model simulations using (a) the original WO10 algorithm and (b) the modified algorithm including the bias correction. (c) PDFs of the effect of the bias correction calculated as (b) minus (a). (d) The ERA-Interim (shaded) and AMIP (contours) z500 composites (anomalies from DJF mean) associated with the corresponding northern $(\mathrm{N})$, central (C), and southern (S) positions. The contour level in (d) is $20 \mathrm{~m}$, with the zero line omitted and negative values dashed. The composites are based on all DJF days when the jet latitude lies within the latitudinal band of the respective jet regime $\left(\mathrm{N}: 58^{\circ} \mathrm{N} \pm 2^{\circ}\right.$; $\mathrm{C}: 45^{\circ} \mathrm{N} \pm 2^{\circ}$; $\mathrm{S}: 36^{\circ} \mathrm{N} \pm 2^{\circ}$ ) using for AMIP the PDF shown in (b): that is, the jet latitude index including the bias correction. (e) The AMIP z500 composites (anomalies from DJF mean) corresponding to the changes in the PDF evoked by the bias correction as shown in (c). See text for more details.

improved agreement with ERA-Interim (Fig. 9b). All three present-day simulations exhibit the trimodal structure and have a wider range of latitudinal variability than using the original WO10 algorithm (cf. Figs. 9a,b). The increase in latitudinal variability and the reduction in occurrence of the central jet regime are not surprising as the bias correction artificially weakens the jet across the central longitudes and strengthens it at high/low latitudes thus fostering fat tails in the PDFs.
However, the successful reproduction of the trimodality is certainly not owed to the bias correction only and rather implies that the multimodal jet latitude behavior is truly included in CCSM4 but was masked by the climatological wind bias when using the original WO10 algorithm. Particularly the fact that the model reproduces the northern, central, and southern peaks of the PDFs at the same latitudes as in ERA-Interim provides confidence. Moreover, the physical meaning of the 
PDFs is tested by analyzing the 500-hPa geopotential height (z500) composites associated with each jet regime. More precisely, the composite analysis provides the average z500 patterns (Fig. 9d) for all winter days when the bias-corrected jet latitude index corresponds to the latitudinal band of the respective jet regime (northern jet: $58^{\circ} \mathrm{N} \pm 2^{\circ}$; central jet: $45^{\circ} \mathrm{N} \pm 2^{\circ}$; southern jet: $36^{\circ} \mathrm{N} \pm 2^{\circ}$ ). The comparison of ERA-Interim (shaded in Fig. 9d) and the present-day model simulations (shown for AMIP; contours in Fig. 9d) exhibits high agreement. The southern jet position corresponds in both cases to a Greenland blocking high, whereas the central (northern) jet regime corresponds to a low (high) pressure center over the central NA. Note also that these large-scale circulation patterns are fully consistent with the results by WO10 (see their Fig. 4).

To verify the physical meaning of our bias correction, we further analyze the circulation patterns associated with the differences between the PDFs before and after the bias correction. For the southern and northern regimes, applying the bias correction leads to a clear increase in the number of days at which the jet is located within the latitudinal band of the respective jet regime (Fig. 9c). The z500 patterns associated with days that are designated to the southern regime only because of the bias correction are shown (for AMIP) as composite 1 in Fig. 9e. Indeed, composite 1 represents the Greenland blocking situation previously diagnosed for the southern regime (Fig. 9d), confirming that the algorithm including the bias correction truly identifies additional days with the correct NA weather situation. Equivalently, composite 2 (Fig. 9e) compares well with the z500 pattern associated with the northern regime in Fig. 9d.

Furthermore, we calculate the z500 composites for the days that are not designated to the central regime anymore when using the bias correction but do so with the original WO10 algorithm (illustrated by the negative frequencies of central regime days in Fig. 9c). Thereby, we need to distinguish between two cases: composite 3 includes all days at which the bias-corrected algorithm points at a latitude south of the central regime, whereas composite 4 samples all days with a more northern jet latitude. Composites 3 and 4 (Fig. 9e) indeed differ from the actual central regime pattern shown in Fig. 9d with composite 3 rather resembling the southern jet regime and composite 4 showing a circulation pattern unrelated to any of the three jet regimes. This confirms that the overestimation of the central jet regime in the present-day model simulations using the original WO10 algorithm (Fig. 9a) is not for physical reasons but rather a problem of the jet latitude index itself as it is contaminated by the model's climatological wind bias.

\section{b. Jet latitude index in paleoclimate simulations}

As a consequence of the aforementioned issues (section 6a), we use our adapted algorithm including the bias correction for the calculation of the daily jet latitude index in all paleoclimate simulations. In doing so, we modify the daily low-level zonal winds of each paleoclimate simulation by correcting for the model bias determined with the corresponding present-day simulation. For all simulations forced with $3^{\circ}$-resolution SSTs and sea ice (Table 1), the winter mean bias calculated as PD3 climatology minus ERA-Interim climatology (see shading in Fig. 2) is subtracted. For all simulations forced with $1^{\circ}$-resolution SSTs and sea ice (Table 1), the bias calculated as PD1 minus ERA-Interim is removed. Following the bias correction, the WO10 algorithm is applied to diagnose the daily jet latitude index, which finally leads to a respective jet latitude PDF for each simulation (Figs. 10 and 11).

In all interglacial simulations (Fig. 10), we find distinct multimodal distributions of the jet latitude index. The central and northern regimes (with the exception of $\mathrm{EEM}_{\mathrm{r} 3}$ ) seem to be consistently favored positions of the NA eddy-driven jet in interglacial climate, whereas the southern position is more fragile. Even in the preindustrial simulation (PI3) the southern peak is not as distinct as in for present-day climate (PD3). This is, however, in agreement with the jet latitude PDFs constructed from 20CR data (Compo et al. 2011), where it was previously shown that the southern regime was quite rare during two recent 20-yr periods (Woollings et al. 2014). Overall, the multimodality still appears as a consistent feature in NA eddy-driven jet latitude variability for interglacial conditions.

Another result is that the $\mathrm{EEM}_{\mathrm{r} 3}$ PDF (highlighted by the thick red line in Fig. 10) lacks the northern peak and includes a relatively large number of days where the jet is located north of $60^{\circ} \mathrm{N}$ (shaded area in Fig. 10). This is unusual compared to all other interglacial simulations, which show the northern peak around $58^{\circ} \mathrm{N}$ and a sharp drop in the distribution farther poleward. More precisely, $\mathrm{EEM}_{\mathrm{r} 3}$ includes 113 days in 30 winters when the jet latitude is $>60^{\circ} \mathrm{N}$. This is in contrast to all other interglacial simulations, which are characterized by a distinctively smaller numbers (average: 44 days; standard deviation: 25 days) for the same quantity. Using Dixon's Q-test statistics (Dean and Dixon 1951), the $\mathrm{EEM}_{\mathrm{r} 3}$ frequency of days $>60^{\circ} \mathrm{N}$ is revealed as a significant outlier at the $1 \%$ level. The significant increase in the number of jet latitude days $>60^{\circ} \mathrm{N}$ in EEMr3 likely relates to its Greenland topography. In contrast to all other interglacial simulations, Greenland's South Dome has been removed in $\mathrm{EEM}_{\mathrm{r} 3}$ (Fig. 1a), so the 


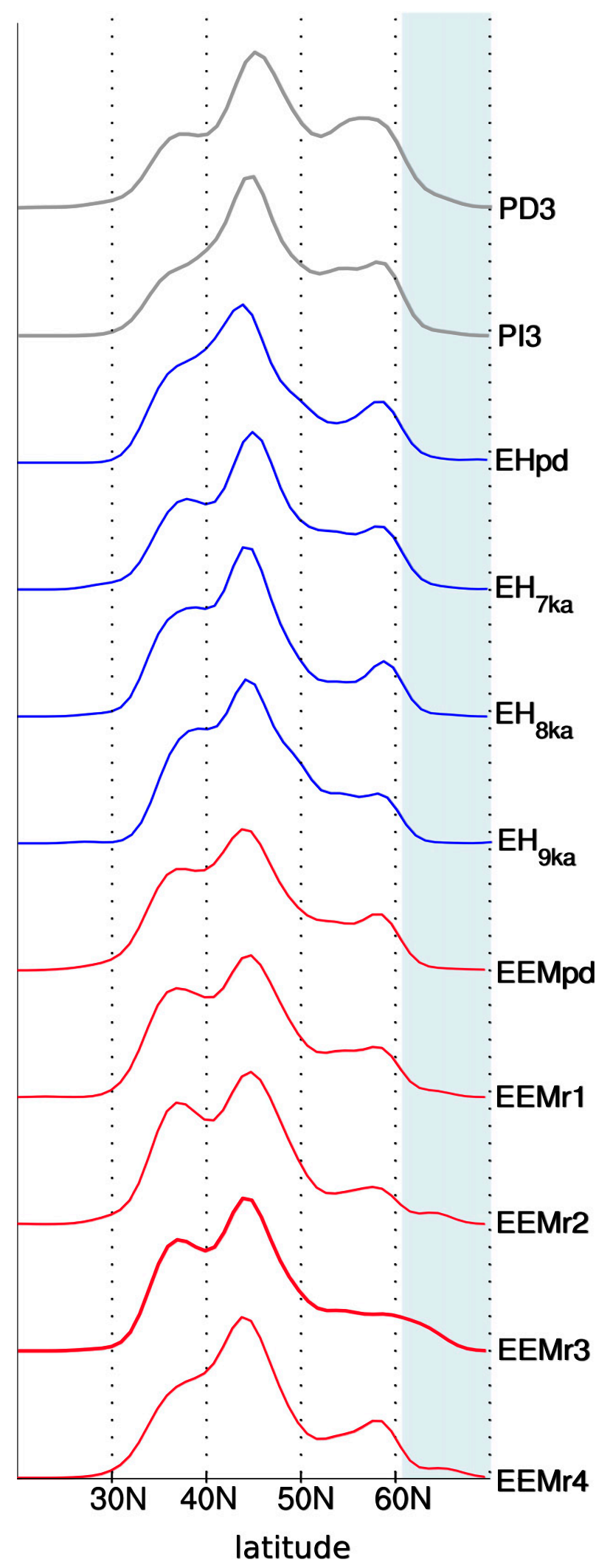

FIG. 10. PDFs of daily DJF jet latitude for the interglacial simulations. Note that the bias correction was applied to all data. topographic barrier for a poleward moving jet is shifted from around $60^{\circ}$ to $70^{\circ} \mathrm{N}$.

The PDFs for the glacial simulations and two sensitivity experiments are presented in Fig. 11. The LGM PDF (green line in Fig. 11a) shows a distinct southward shift of the NA eddy-driven jet latitude compared to present day as previously diagnosed from the winter mean fields (e.g., Fig. 4). Moreover, LGM features a narrow unimodal distribution in terms of daily jet position. Consequently, the latitudinal shifts and multimodality of the jet found for interglacial conditions are clearly suppressed in a glacial climate as the glacial winter jet is predominantly located around $38^{\circ} \mathrm{N}$. Furthermore, the PDFs of the two sensitivity experiments, $\mathrm{PI}_{\mathrm{LGM}}$ and $\mathrm{LGM}_{\mathrm{PD}}$, represent intermediate states being equal to neither LGM nor PI1. However, the presence of the LGM-state LIS in PI $_{\text {LGM }}$ causes a more LGM-like unimodal PDF, whereas $\mathrm{LGM}_{\mathrm{PD}}$ still shows a rather broad jet latitude distribution. This is consistent with the results from section 4 indicating that the presence of large glacial ice sheets dominates the NA jet behavior with other glacial boundary conditions being of secondorder importance.

The jet latitude distributions of the MIS4 experiments (Fig. 11b) are all marked by rather narrow and unimodal PDFs. Furthermore, the comparison of the individual MIS4 simulations using different ice-sheet topographies shows that both the southward shift and the associated decrease in jet latitude variability scales with the height of the LIS. Hence, the narrowest and most strongly shifted PDF is found for the $125 \%$ LGM-size LIS (MIS4 $4_{125}$ ), followed by $100 \% \quad\left(\right.$ MIS4 $\left._{\text {LGM }}\right), \quad 76 \% \quad\left(\right.$ MIS4 $\left._{\text {lowFS }_{1}}\right)$, $67 \%$ (MIS4 67 ), and $46 \%$ (MIS4 $4_{\text {lowLIS }}$ ) LIS height. Consequently, the MIS4 simulations (as well as the LGM run and the sensitivity experiments) suggest a simple relationship between mean jet position and the daily latitudinal variability: the stronger the southward shift, the narrower and more unimodal the jet latitude PDF (Fig. 11b).

\section{c. Leading modes of jet variability}

Complementary to the jet latitude index, we assess the intraseasonal variability of the NA eddy-driven jet using an EOF analysis. We define variability patterns as the first and second EOFs of the daily, low-level (averaged across $925-700 \mathrm{hPa}$ ), 10-day low-pass filtered zonal mean zonal winds, averaged over the longitudes from $60^{\circ} \mathrm{W}$ to $0^{\circ}$ and extending over the latitudes from $15^{\circ}$ to $75^{\circ} \mathrm{N}$. The EOF analysis provides the patterns of dominant variability in terms of jet speed and latitudinal position. However, it does exclude meridional variability (as does the jet latitude index), since zonal mean zonal winds are used. 
a) glacial vs. interglacial jet latitude PDFs

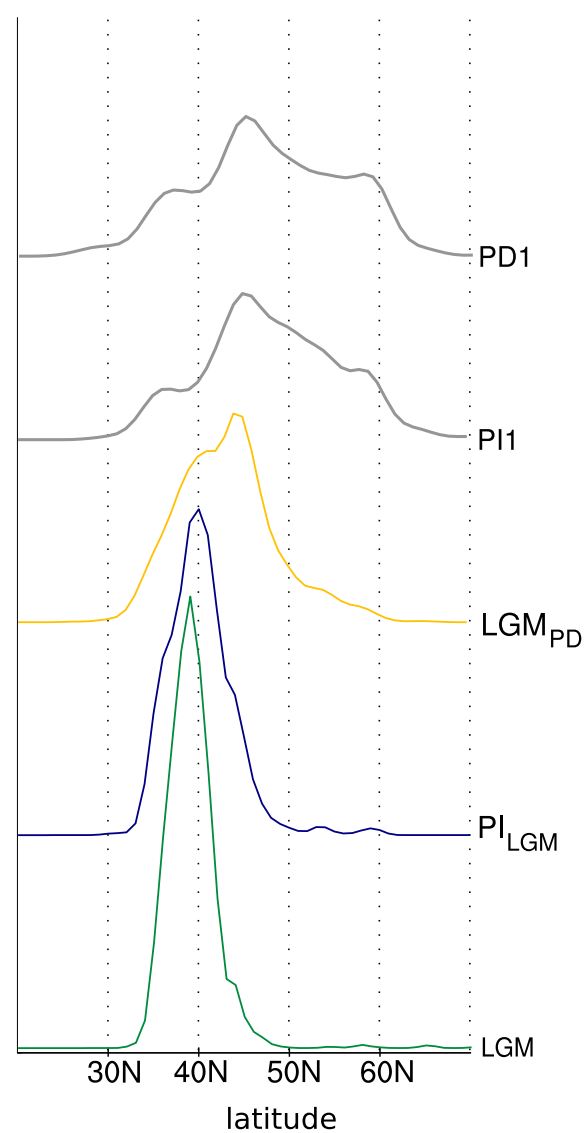

b) MIS4 jet latitude PDFs

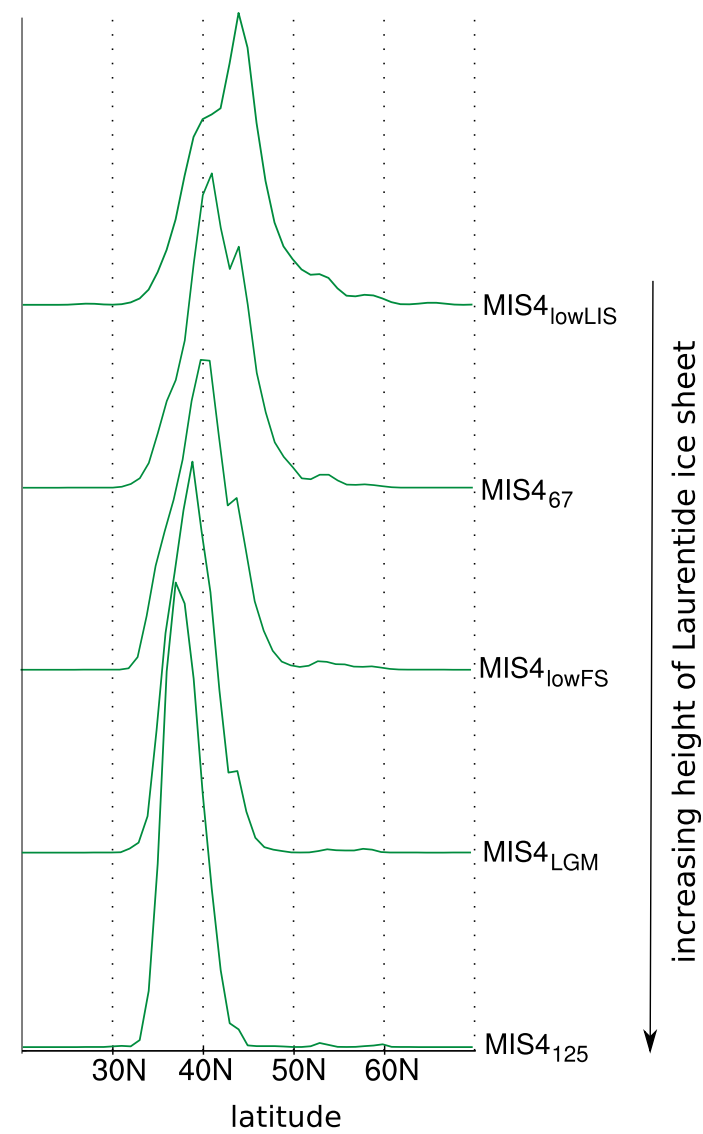

FIG. 11. PDFs of daily DJF jet latitude for the glacial simulations. (a) Influence of the glacial vs interglacial boundary conditions. (b) Dependence of the PDFs on the height of the Laurentide ice sheet according to the MIS4 simulations. Note that the bias correction was applied to all data.

The EOFs as well as the composites of low-level zonal mean zonal winds regressed on the $\mathrm{PC} 1 / \mathrm{PC} 2$ are presented in Fig. 12 for ERA-Interim, PD3, and LGM. Thereby, PD3 is representative for all interglacial simulations, whereas LGM designates the maximum glacial state. In agreement with previous studies (Eichelberger and Hartmann 2007; Barnes and Polvani 2013), we find for the present-day climate (ERA-Interim and PD3; Figs. 12a,b) that the leading mode (EOF1) of jet variability is related to distinct meridional shifts in the jet positions (the so-called wobbling), whereas the second mode (EOF2) is an acceleration-deceleration of the jet speed (the so-called pulsing). Note that EOF1 and EOF 2 combine in both cases to more than $80 \%$ of the total variance. Hence, the wobbling and pulsing almost account for the full variability of the NA eddy-driven jet in winter. Besides, the good agreement of the model compared to ERA-Interim confirms that CCSM4 includes a realistic representation of the NA eddy-driven winter jet variability.
Moreover, the PD3 simulation is in agreement with ERA-Interim with respect to the PC1/PC2 composites in low-level zonal mean zonal wind (cf. Figs. 12d,g with Figs. 12e,h). The positive PC1 composites (red lines in Figs. 12d,e) denote a jet shifted poleward with respect to its winter mean position (indicated by the black vertical reference line), whereas the negative PC1 composites (blue lines in Figs. 12d,e) show an equatorward shift. Consequently, ERA-Interim and PD3 are also in accordance regarding the net effect of the EOF1 illustrated by the positive minus negative composite differences (green lines in Figs. 12d,e). Investigating the PC2 composites of ERA-Interim and PD3 (Figs. 12g,h), we find that the EOF2 distinguishes between an accelerated (positive composites: red lines) and an almost absent jet (negative composites: blue lines). Again, PD3 and ERA-Interim also correspond with respect to the amplitude of the EOF2 net effect, as indicated by the PC2 composite differences (green lines in Figs. 12g,h). 
ERAi
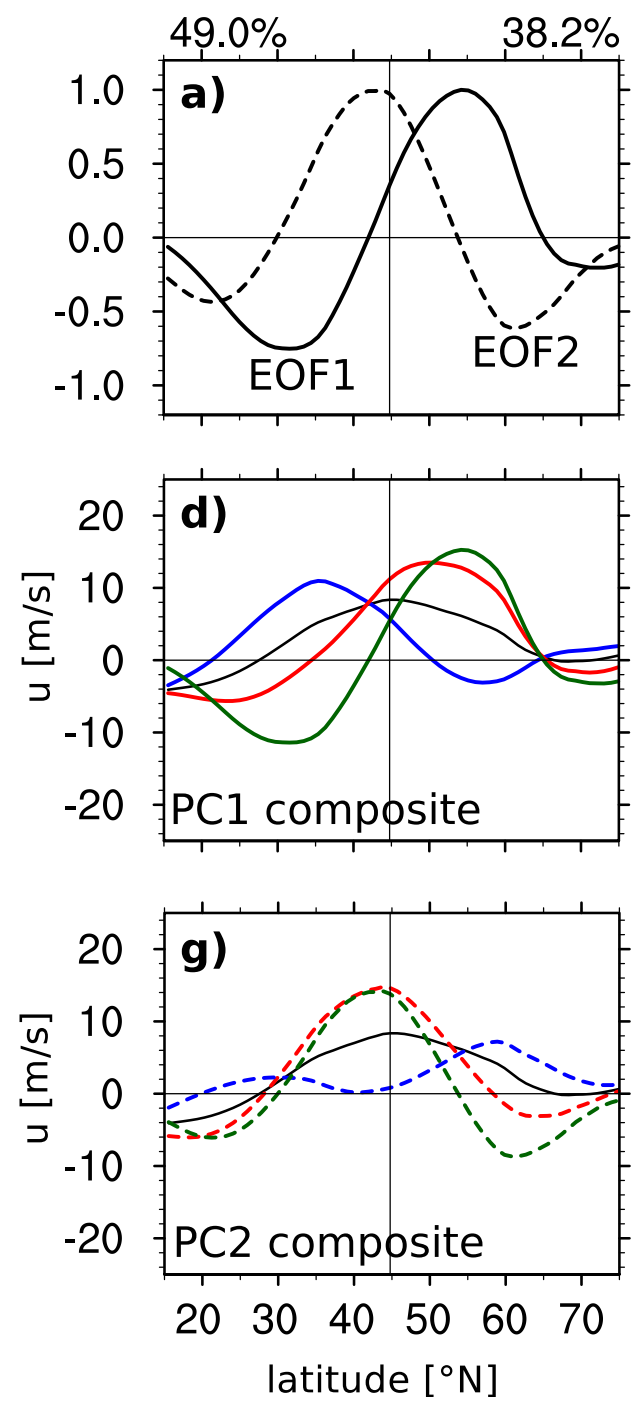

interglacial (PD3)
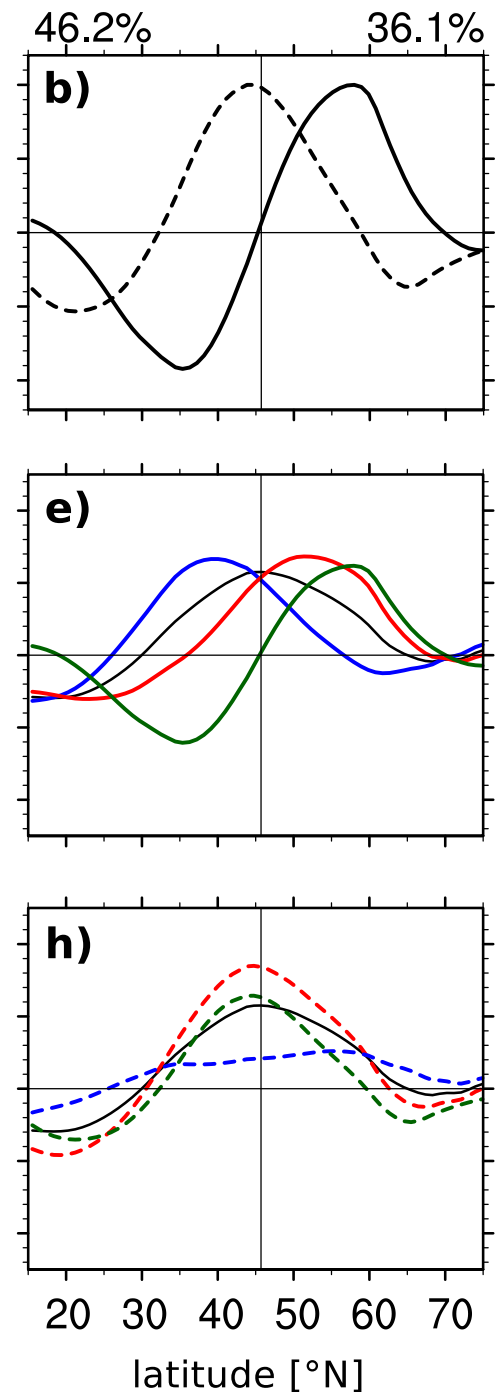

glacial (LGM)
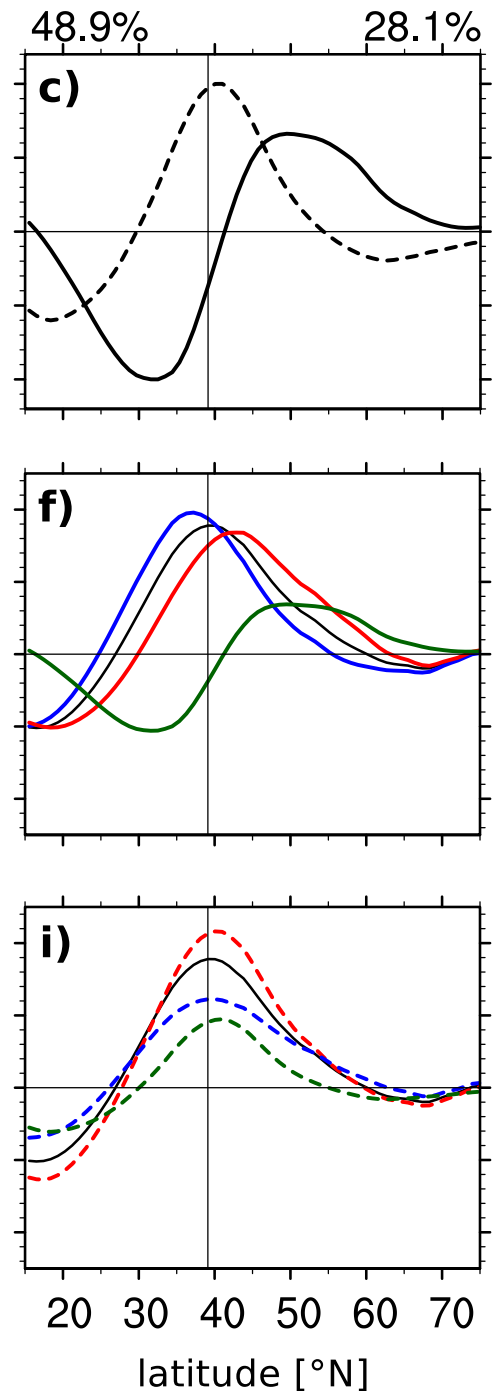

FIG. 12. Daily DJF NA eddy-driven jet variability for (a) ERA-Interim, (b) interglacial simulations (shown for PD3), and (c) glacial simulations (shown for LGM) based on the EOF analysis. Normalized daily zonal mean zonal wind is associated with EOF1 (solid) and EOF2 (dashed). The explained variance by EOF1 (EOF2) is indicated at the top left (right). (d)-(f) Daily zonal mean zonal wind PC1 composite $\left(\mathrm{m} \mathrm{s}^{-1}\right)$ associated with the EOF1 pattern (the wobble). (g)-(i) Daily zonal mean zonal wind PC2 composite ( $\left.\mathrm{m} \mathrm{s}^{-1}\right)$ associated with the EOF2 pattern (the pulse). Note that in (d)-(i) the red (blue) lines denote the positive (negative) composite mean: that is, the mean of all days when the standardized PC1/PC2 time series is greater than 1 (less than -1 ). Further, the green lines denote the resulting positive minus negative composite differences and the black line denotes the winter mean zonal wind. In all panels, the vertical grid line indicates the DJF mean jet latitude of the respective reanalysis/simulation.

Calculating EOF1 and EOF2 for all paleoclimate simulations (mostly not shown), the leading modes of NA jet variability are similar, even under LGM conditions (Fig. 12c). Hence, the internal modes of jet variability seem to be rather stable, regardless of the climate state. In all cases, the wobbling dominates over the pulsing. However, the wobbling and pulsing are less efficient under glacial conditions compared to interglacial climate conditions, as apparent from the PC1/PC2 composites (cf.
Figs. 12e,h with Figs. 12f,i). During interglacials (shown for PD3; Fig. 12e), we find an EOF1-related wobbling between the negative phase (jet located at $\sim 38^{\circ} \mathrm{N}$ ) and the positive phase (jet located at $\sim 51^{\circ} \mathrm{N}$ ) that corresponds to a latitudinal shift of $13^{\circ}$. In contrast, for glacial climate conditions (shown for LGM; Fig. 12f), the wobbling results in a strongly decreased meridional shift of just $6^{\circ}$, as illustrated by the negative and the positive LGM PC1 composites. Hence, although the magnitude of the wind 
anomalies corresponding to net effect of the wobbling is similar in interglacial and glacial simulations (cf. green lines in Figs. 12e,f), the meridional variability of the position of the jet (i.e., the maximum zonal wind) is clearly decreased during glacials. This is related to the fact that the winter mean zonal wind is strongly enhanced and the jet is more distinctively defined under glacial compared to interglacial conditions (cf. black lines in Figs. 12e,f). Consequently, in relative terms the wobbling becomes less important under glacial conditions as the increase in the jet's mean strength is not accompanied by an increase in variability. This corresponds to the narrow PDFs for glacial conditions measured by the jet latitude index (Fig. 11), suggesting a highly persistent NA eddy-driven jet for full glacial conditions.

The magnitude of the pulsing (EOF2 variability) on the glacial jet is weaker than for interglacial conditions, as indicated by the PC2 composite differences (cf. green lines in Figs. 12h,i). The EOF2 composites in the interglacial and glacial simulations further differ because the pulsing is added to different winter mean zonal winds (black lines in Figs. 12h,i). For interglacial conditions, the pulsing distinguishes between a weak $\left(\sim 5 \mathrm{~m} \mathrm{~s}^{-1}\right)$ and a strong $\left(\sim 17 \mathrm{~m} \mathrm{~s}^{-1}\right)$ jet (blue and red lines in Fig. $12 \mathrm{~h}$ ), whereas the PC2 composite for LGM (Fig. 12i) indicates that the pulsing just distinguishes between a strong $\left(\sim 13 \mathrm{~m} \mathrm{~s}^{-1}\right)$ and an even stronger $\left(\sim 22 \mathrm{~m} \mathrm{~s}^{-1}\right)$ jet. Consequently, the winter mean acceleration of the glacial NA eddy-driven jet affects both the positive and negative phases of the EOF2 composite.

\section{Discussion and conclusions}

This study investigates the behavior of the NA eddydriven jet during interglacial and glacial winter climates using simulations with the atmosphere-land-only setup of CCSM4. The analysis addresses changes in the winter mean jet and its links to the leading mechanism: namely, the role of stationary and transient eddies, which provide the zonal momentum. Beside the assessment of the winter mean jet, the interglacial and glacial daily jet variability are compared with each other using two independent measures.

Though modifications to both external forcing and ice-sheet topography are included, all interglacial simulations exhibit NA jet characteristics closely resembling the state currently observed. The early Holocene and Eemian orbital forcing solely lead to a slight southward shift of the NA eddy-driven jet in terms of winter mean position. However, the stationary waves and transient eddies are remarkably stable during interglacial conditions ensuring a present-day-like NA eddy-driven jet. The moderate changes in the $\mathrm{NH}$ topography during past interglacial periods show only a limited impact on the NA eddy-driven jet. This is likely due to the high latitudinal location of the topographic changes (mostly $>60^{\circ} \mathrm{N}$ ) thus lying too far poleward to substantially affect the jet stream and the eddies in the midlatitudes.

The NA eddy-driven jet's intraseasonal variability is also fairly stable among all interglacial climates tested here, as confirmed by the two jet variability analyses. The latitudinal wobbling is the dominant kind of interglacial NA jet variability as revealed by the EOF analysis. According to the jet latitude index developed by WO10, the intraseasonal latitudinal distribution of the jet further exhibits the trimodality. Thus, the existence of three preferred latitudinal positions is confirmed as the typical interglacial character of the NA eddy-driven jet during winter and hence is not unique to the present-day era. However, though the multimodality is a very consistent feature, some variability exists with respect to the actual occurrence of the preferred jet positions and not all three jet regimes emerge as clearly within each of the interglacial simulations. This is, nevertheless, consistent with the results by Woollings et al. (2014), who found similar variations in the jet latitude distributions among different periods of the 20CR reanalysis dataset covering the last $140 \mathrm{yr}$. Somewhat contrary to the general stability of the trimodality in interglacial simulations, one Eemian simulation where Greenland's South Dome ice is removed (EEMr3 in Fig. 1) lacks the northern jet regime and shows a significant increase in the number of days at which the jet stays poleward of $60^{\circ} \mathrm{N}$. This is in contrast to all other interglacial simulations, which include a GrIS reaching as far south as at present day and thus have a substantial topographic feature in the NA sector poleward of $60^{\circ} \mathrm{N}$. This result suggests that south Greenland's topography is needed for establishing the northern peak in the multimodal distribution, as Greenland seems to serve as physical northern boundary for the poleward moving jet.

During glacial times, the winter mean NA eddydriven jet is strongly accelerated and shifted equatorward. Moreover, the intraseasonal variability in terms of latitudinal position is highly reduced and the jet latitude index is unimodal and indicates a very persistent glacial jet. In agreement with previous studies (Cook and Held 1988; Kageyama and Valdes 2000; Pausata et al. 2011), the glacial ice-sheet topography, in particular the presence of the LIS, is identified as primary driver of these glacial-interglacial jet changes. The higher the LIS, the more distinct the glacial character of the NA eddydriven jet. The presence of a large LIS causes an amplification of the Rocky Mountains' effect on the NH stationary wave pattern (Brayshaw et al. 2009) as the dominant orographic barrier of the North American 
continent is extended both eastward and southward. As a result, the stationary wave pattern is strengthened and the NA eddy-driven jet is modified by distinct stationary eddy momentum flux anomalies. In addition, the transient eddies are also affected by the glacial nontopographic forcings (i.e., orbital forcing, GHGs, and SSTs), supporting the acceleration and southward shift of the jet.

The dominant role of the topography in distinguishing between an interglacial and a glacial type jet is further proved by two sensitivity studies, which test the isolated effect of the glacial ice sheets on the one hand and the glacial external forcing on the other hand. Thereby, the preindustrial simulation including LGM-size ice sheets leads to typical glacial jet characteristics whereas the LGM simulation including present-day topography leads to an intermediate state of the jet. Hence, the nontopographic glacial boundary conditions are of secondary importance but nevertheless necessary to explain the full LGM minus present-day differences with respect to both the mean and the variability of the NA eddy-driven jet.

The strongly reduced latitudinal variability of the glacial eddy-driven jet is in agreement with $\mathrm{Li}$ and Battisti (2008) and is likely connected to accompanied changes in the NA storm track that feedback on the variability of the mean flow through anomalous Rossby wave breaking (Riviere et al. 2010). More precisely, increased occurrence of cyclonic wave breaking at the cost of anticyclonic wave breaking potentially leads to the equatorward shift of the glacial jet (Laine et al. 2009), whereas changes in the dispersion of wavebreaking events are responsible for weaker latitudinal fluctuations of the NA eddy-driven jet (Riviere et al. 2010). In contrast to Riviere et al. (2010) though, we find that the latitudinal wobbling remains the primary type of NA jet variability and dominates the jet pulsing also during glacial times. The reduction in terms of daily latitudinal shifts is further observed to depend on the southward shift of the winter mean jet. This relationship between jet variability and mean latitudinal position is in line with Barnes and Polvani (2013), who define three kinds of jet variability regimes. The NA eddy-driven jet in glacial times corresponds to their second regime: that is, a low-latitude eddy-driven jet where the meridional variability is suppressed by the presence of strong subtropical winds. At present, these characteristics apply to the North Pacific jet. In contrast, the NA eddy-driven jet under interglacial conditions falls into the third category by Barnes and Polvani (2013): that is, a distinct meridionally wobbling eddy-driven jet located neither too close to the subtropical jet nor too far poleward, where meridional variability is suppressed by weak background vorticity gradients.
As a consequence, for full glacial conditions the Atlantic jet in the $\mathrm{NH}$ becomes more Pacific-like with a greater jet speed, a more equatorward position, and therefore limited meridional variability (Eichelberger and Hartmann 2007; Barnes and Polvani 2013). This transformation in eddy-driven jet character is closely related to concurrent changes in the storm track, which also shows rather Pacific-like conditions in glacial climates with the maximum eddy activity shifted toward the eastern boundary of the ocean basin. The stationary wave response seems key in this and also shows rather Pacific-like characteristics: the present-day stationary wave train over the Pacific is more southward oriented than over the Atlantic, as is the Atlantic wave under glacial conditions (see Fig. 5). This seems plausible as the LIS makes the North American orography more similar to the Tibetan Plateau (i.e., higher and more longitudinally expansive), implying that similar shapes in large-scale topography lead to comparable responses in terms of atmospheric circulation. However, some fundamental differences between the glacial Atlantic jet and the interglacial Pacific jet certainly remain, as the effect of the Tibetan Plateau on the stationary wave pattern over Asia and the Pacific is predominantly associated with diabatic heating (Liu et al. 2007). This is clearly different for North America covered by an extensive LIS. In addition, the Pacific sector itself is a considerable source for thermal driving of the midlatitude jet, whereas in the tropical Atlantic the thermal heating and its effect on the midlatitude atmospheric circulation are of relatively lesser importance ( $\mathrm{Li}$ and Wettstein 2012).

The strong dependence of the glacial jet character on the height of the LIS supports the simulations by Löfverström et al. (2014). Accordingly, the atmospheric circulation of the LGM should be regarded as an extreme glacial state. Indeed, the North American ice volume was below LGM level for almost the entire last glacial period (Kleman et al. 2013), thus limiting the stationary wave response and the associated effects on the NA eddydriven jet. Consequently, the state of the NA atmospheric circulation was likely not as far from interglacial conditions during most of the Quaternary period as during LGM. The almost linear relationship between LIS height and atmospheric response identified among the MIS4 simulations further suggests that the state of the NA winter circulation might be coarsely estimated based on proxies providing information about the LIS volume.

We successfully implemented a bias correction method for application to the jet latitude analysis introduced by WO10. After the removal of the climatological wind bias (i.e., an overestimation of the zonal wind speed around $45^{\circ} \mathrm{N}$ ), the model appears to simulate the three regime structure of jet variability with reasonable success. In contrast, the original WO10 algorithm applied to the 
model simulations result in unimodal distributions around the central jet regime resembling the findings by Hannachi et al. (2013), who found that none of the CMIP3 models was able to simulate the trimodal jet latitude distribution. Our analysis reveals that the WO10 algorithm underestimates the model's latitudinal variability by mistake, as it ignores variability in the wind field beyond the daily maximum wind. A reasonable representation of the intraseasonal jet variability in CCSM4 is confirmed by the EOF analysis, showing that latitudinal wobbling is of similar amplitude as in ERA-Interim. Nevertheless, the presence of the winter mean bias in the NA zonal winds in CCSM4 remains an issue, as it is coupled to the underestimation of blockings, especially over Europe (Anstey et al. 2013; Masato et al. 2013). Recent work has shown that such biases can potentially be reduced through a better representation of the stratosphere (Anstey et al. 2013; Shaw et al. 2014), increased resolution in surface topography (Berckmans et al. 2013), or even improved model physics (Jung et al. 2010).

As long as the models include such mean biases, however, the WO10 jet latitude analysis can be of limited value when applied to model simulations (e.g., Hannachi et al. 2013; Anstey et al. 2013). Correspondingly, it would be of great interest to apply the bias correction method presented here to the CMIP3/CMIP5 archive in order to revisit the model's capability in simulating the trimodality. If the trimodal behavior indeed were present within different climate models, it would (i) strengthen the confidence in the results obtained here, (ii) imply that the stateof-the-art climate models comprise reasonable ability in representing the dominant NA atmospheric winter variability though including distinct mean biases, and (iii) motivate to use these models in order to assess the stability of the trimodality under future climate conditions.

Acknowledgments. We kindly thank Andreas Born, Vidya Varma, Matthias Prange, and Alex Robinson for providing data. We are also grateful for the valuable inputs by Justin Wettstein and an anonymous reviewer. All simulations were produced at the Swiss National Supercomputing Centre (CSCS). This research is funded by the European Union's Seventh Framework Programme (FP7/2007-2013) under Grant Agreement 243908: "Past4Future. Climate change-Learning from the past climate." We further acknowledge financial support by the Swiss Federal Nuclear Safety Inspectorate (ENSI).

\section{REFERENCES}

Anstey, J. A., and Coauthors, 2013: Multi-model analysis of Northern Hemisphere winter blocking: Model biases and the role of resolution. J. Geophys. Res., 118, 3956-3971, doi:10.1002/ jgrd.50231.
Athanasiadis, P. J., J. M. Wallace, and J. J. Wettstein, 2010: Patterns of wintertime jet stream variability and their relation to the storm tracks. J. Atmos. Sci., 67, 1361-1381, doi:10.1175/ 2009JAS3270.1.

Barnes, E. A., and L. Polvani, 2013: Response of the midlatitude jets, and of their variability, to increased greenhouse gases in the CMIP5 models. J. Climate, 26, 7117-7135, doi:10.1175/ JCLI-D-12-00536.1.

Berckmans, J., T. Woollings, M.-E. Demory, P.-L. Vidale, and M. Roberts, 2013: Atmospheric blocking in a high resolution climate model: Influences of mean state, orography and eddy forcing. Atmos. Sci. Lett., 14, 34-40, doi:10.1002/asl2.412.

Blackmon, M. L., 1976: A climatological spectral study of the $500 \mathrm{mb}$ geopotential height of the Northern Hemisphere. J. Atmos. Sci., 33, 1607-1623, doi:10.1175/1520-0469(1976)033<1607: ACSSOT $>2.0 . \mathrm{CO} ; 2$.

Born, A., and K. H. Nisancioglu, 2012: Melting of northern Greenland during the last interglaciation. Cryosphere, 6, 1239-1250, doi:10.5194/tc-6-1239-2012.

Brayshaw, D. J., B. Hoskins, and M. Blackburn, 2009: The basic ingredients of the North Atlantic storm track. Part I: Land-sea contrast and orography. J. Atmos. Sci., 66, 2539-2558, doi:10.1175/2009JAS3078.1.

Compo, G. P., and Coauthors, 2011: The Twentieth Century Reanalysis Project. Quart. J. Roy. Meteor. Soc., 137, 1-28, doi:10.1002/qj.776.

Cook, K. H., and I. M. Held, 1988: Stationary waves of the ice age climate. J. Climate, 1, 807-819, doi:10.1175/1520-0442(1988)001<0807: SWOTIA $>2.0 . \mathrm{CO} ; 2$.

Dean, R., and W. Dixon, 1951: Simplified statistics for small numbers of observations. Anal. Chem., 23, 636-638, doi:10.1021/ ac60052a025.

Dee, D. P., and Coauthors, 2011: The ERA-Interim reanalysis: Configuration and performance of the data assimilation system. Quart. J. Roy. Meteor. Soc., 137, 553-597, doi:10.1002/ qj. 828 .

Eichelberger, S. J., and D. L. Hartmann, 2007: Zonal jet structure and the leading mode of variability. J. Climate, 20, 5149-5163, doi:10.1175/JCLI4279.1.

Gent, P. R., and Coauthors, 2011: The Community Climate System Model version 4. J. Climate, 24, 4973-4991, doi:10.1175/ 2011JCLI4083.1.

Gladstone, R. M., and Coauthors, 2005: Mid-Holocene NAO: A PMIP2 model intercomparison. Geophys. Res. Lett., 32, L16707, doi:10.1029/2005GL023596.

Hannachi, A., E. A. Barnes, and T. Woollings, 2013: Behaviour of the winter North Atlantic eddy-driven jet stream in the CMIP3 integrations. Climate Dyn., 41 (3-4), 995-1007, doi:10.1007/ s00382-012-1560-4.

Hartmann, D. L., 2007: The atmospheric general circulation and its variability. J. Meteor. Soc. Japan, 85B, 123-143, doi:10.2151/ jmsj.85B.123.

Held, I. M., M. F. Ting, and H. L. Wang, 2002: Northern winter stationary waves: Theory and modeling. J. Climate, 15, 2125-2144, doi:10.1175/1520-0442(2002)015<2125:NWSWTA $>2.0$.CO;2.

Hofer, D., C. C. Raible, A. Dehnert, and J. Kuhlemann, 2012a: The impact of different glacial boundary conditions on atmospheric dynamics and precipitation in the North Atlantic region. Climate Past, 8, 935-949, doi:10.5194/cp-8-935-2012.

,,-- N. Merz, A. Dehnert, and J. Kuhlemann, 2012b: Simulated winter circulation types in the North Atlantic and European region for preindustrial and glacial conditions. Geophys. Res. Lett., 39, L15805, doi:10.1029/2012GL052296. 
Hoskins, B. J., and D. J. Karoly, 1981: The steady linear response of a spherical atmosphere to thermal and orographic forcing. J. Atmos. Sci., 38, 1179-1196, doi:10.1175/ 1520-0469(1981)038<1179:TSLROA > 2.0.CO;2.

_ I. N. James, and G. H. White, 1983: The shape, propagation and mean-flow interaction of large-scale weather systems. J. Atmos. Sci., 40, 1595-1612, doi:10.1175/ 1520-0469(1983)040<1595:TSPAMF > 2.0.CO;2.

Hunke, E. C., and W. H. Lipscomb, 2008: CICE: The Los Alamos Sea Ice Model: Documentation and software user's manual, version 4.0. Los Alamos National Laboratory Tech. Rep. LA-CC-06-012, 76 pp.

Hurrell, J. W., J. J. Hack, D. Shea, J. M. Caron, and J. Rosinski, 2008: A new sea surface temperature and sea ice boundary dataset for the Community Atmosphere Model. J. Climate, 21, 5145-5153, doi:10.1175/2008JCLI2292.1.

Jung, T., and Coauthors, 2010: The ECMWF model climate: Recent progress through improved physical parametrizations. Quart. J. Roy. Meteor. Soc., 136, 1145-1160, doi:10.1002/ qj.634.

Justino, F., and W. R. Peltier, 2005: The glacial North Atlantic Oscillation. Geophys. Res. Lett., 32, L21803, doi:10.1029/ 2005GL023822.

_ _ A. Timmermann, U. Merkel, and E. P. Souza, 2005: Synoptic reorganization of atmospheric flow during the Last Glacial Maximum. J. Climate, 18, 2826-2846, doi:10.1175/JCLI3403.1.

Kageyama, M., and P. J. Valdes, 2000: Impact of the North American ice-sheet orography on the Last Glacial Maximum eddies and snowfall. Geophys. Res. Lett., 27, 1515-1518, doi:10.1029/1999GL011274.

Kleman, J., J. Fastook, K. Ebert, J. Nilsson, and R. Caballero, 2013: Pre-LGM Northern Hemisphere ice sheet topography. Climate Past, 9, 2365-2378, doi:10.5194/cp-9-2365-2013.

Laine, A., and Coauthors, 2009: Northern Hemisphere storm tracks during the Last Glacial Maximum in the PMIP2 oceanatmosphere coupled models: Energetic study, seasonal cycle, precipitation. Climate Dyn., 32, 593-614, doi:10.1007/ s00382-008-0391-9.

Li, C., and D. S. Battisti, 2008: Reduced Atlantic storminess during Last Glacial Maximum: Evidence from a coupled climate model. J. Climate, 21, 3561-3579, doi:10.1175/2007JCLI2166.1.

— jet variability in reanalysis. J. Climate, 25, 1587-1596, doi:10.1175/JCLI-D-11-00145.1.

Liu, Y., B. Hoskins, and M. Blackburn, 2007: Impact of Tibetan orography and heating on the summer flow over Asia J. Meteor. Soc. Japan, 85B, 1-19.

Löfverström, M., R. Caballero, J. Nilsson, and J. Kleman, 2014: Evolution of the large-scale atmospheric circulation in response to changing ice sheets over the last glacial cycle. Climate Past, 10, 1453-1471, doi:10.5194/cp-10-1453-2014.

Mak, M. K., and M. Cai, 1989: Local barotropic instability. J. Atmos. Sci., 46, 3289-3311, doi:10.1175/1520-0469(1989)046<3289: $\mathrm{LBI}>2.0 . \mathrm{CO} ; 2$.

Masato, G., B. J. Hoskins, and T. Woollings, 2013: Winter and summer Northern Hemisphere blocking in CMIP5 models J. Climate, 26, 7044-7059, doi:10.1175/JCLI-D-12-00466.1.

Merz, N., C. C. Raible, H. Fischer, V. Varma, M. Prange, and T. F. Stocker, 2013: Greenland accumulation and its connection to the large-scale atmospheric circulation in ERA-Interim and paleoclimate simulations. Climate Past, 9, 2433-2450, doi:10.5194/ cp-9-2433-2013.

, A. Born, C. C. Raible, H. Fischer, and T. F. Stocker, 2014a: Dependence of Eemian Greenland temperature reconstructions on the ice sheet topography. Climate Past, 10, 1221-1238, doi:10.5194/cp-10-1221-2014.

— , G. Gfeller, A. Born, C. C. Raible, T. F. Stocker, and H. Fischer, 2014b: Influence of ice sheet topography on Greenland precipitation during the Eemian interglacial. J. Geophys. Res. Atmos., 119, 10 749-10768, doi:10.1002/2014JD021940.

Neale, R. B., and Coauthors, 2010: Description of the NCAR Community Atmosphere Model (CAM4). National Center for Atmospheric Research Tech. Rep. NCAR/TN+STR, 194 pp.

NEEM community members, 2013: Eemian interglacial reconstructed from a Greenland folded ice core. Nature, 493, 489-494, doi:10.1038/nature11789.

Oleson, K., and Coauthors, 2010: Technical description of version 4.0 of the Community Land Model (CLM). National Center for Atmospheric Research Tech. Note NCAR/TN-478+STR, 257 pp., doi:10.5065/D6FB50WZ.

Pausata, F. S. R., C. Li, J. J. Wettstein, M. Kageyama, and K. H. Nisancioglu, 2011: The key role of topography in altering North Atlantic atmospheric circulation during the last glacial period. Climate Past, 7, 1089-1101, doi:10.5194/cp-7-1089-2011.

Peltier, W. R., 2004: Global glacial isostasy and the surface of the ice-age Earth: The ICE-5G (VM2) model and Grace. Annu. Rev. Earth Planet. Sci., 32, 111-149, doi:10.1146/ annurev.earth.32.082503.144359.

Riviere, G., A. Laine, G. Lapeyre, D. Salas-Melia, and M. Kageyama, 2010: Links between Rossby wave breaking and the North Atlantic Oscillation-Arctic Oscillation in present-day and Last Glacial Maximum climate simulations. J. Climate, 23, 2987-3008, doi:10.1175/2010JCLI3372.1.

Robinson, A., R. Calov, and A. Ganopolski, 2011: Greenland ice sheet model parameters constrained using simulations of the Eemian interglacial. Climate Past, 7, 381-396, doi:10.5194/ cp-7-381-2011.

Scaife, A. A., and Coauthors, 2011: Improved Atlantic winter blocking in a climate model. Geophys. Res. Lett., 38, L23703, doi:10.1029/2011GL049573.

Shaw, T. A., J. Perlwitz, and O. Weiner, 2014: Tropospherestratosphere coupling: Links to North Atlantic weather and climate, including their representation in CMIP5 models. J. Geophys. Res., 119, 5864-5880, doi:10.1002/2013JD021191.

Silverman, B. W., 1981: Using kernel density estimates to investigate multimodality. J. Roy. Stat. Soc., 43B, 97-99.

Trenberth, K. E., 1986: An assessment of the impact of transient eddies on the zonal flow during a blocking episode using localized Eliassen-Palm flux diagnostics. J. Atmos. Sci., 43, 2070-2087, doi:10.1175/1520-0469(1986)043<2070:AAOTIO>2.0.CO;2.

Wettstein, J. J., and J. M. Wallace, 2010: Observed patterns of month-to-month storm-track variability and their relationship to the background flow. J. Atmos. Sci., 67, 1420-1437, doi:10.1175/2009JAS3194.1.

Woollings, T., A. Hannachi, and B. Hoskins, 2010: Variability of the North Atlantic eddy-driven jet stream. Quart. J. Roy. Meteor. Soc., 136, 856-868, doi:10.1002/qj.625.

—, C. Czuchnicki, and C. Franzke, 2014: Twentieth century North Atlantic jet variability. Quart. J. Roy. Meteor. Soc., 140, 783-791, doi:10.1002/qj.2197. 